\title{
Evaluating and constraining ice cloud parameterizations in CAM5 using aircraft measurements from the SPARTICUS campaign
}

\author{
K. Zhang ${ }^{1}$, X. Liu ${ }^{1}$, M. Wang ${ }^{1}$, J. M. Comstock ${ }^{1}$, D. L. Mitchell ${ }^{2}$, S. Mishra ${ }^{2,3}$, and G. G. Mace \\ ${ }^{1}$ Pacific Northwest National Laboratory, Richland, WA, USA \\ ${ }^{2}$ Desert Research Institute, Reno, NV, USA \\ ${ }^{3}$ Cooperative Institute for Mesoscale Meteorological Studies (CIMMS), Norman, OK, USA \\ ${ }^{4}$ Department of Meteorology, University of Utah, Salt Lake City, UT, USA
}

Correspondence to: K. Zhang (kai.zhang@pnnl.gov)

Received: 21 November 2012 - Published in Atmos. Chem. Phys. Discuss.: 11 January 2013

Revised: 22 April 2013 - Accepted: 22 April 2013 - Published: 14 May 2013

\begin{abstract}
This study uses aircraft measurements of relative humidity and ice crystal size distribution collected during the SPARTICUS (Small PARTicles In CirrUS) field campaign to evaluate and constrain ice cloud parameterizations in the Community Atmosphere Model version 5. About 200h of data were collected during the campaign between January and June 2010, providing the longest aircraft measurements available so far for cirrus clouds in the midlatitudes. The probability density function (PDF) of ice crystal number concentration $\left(N_{\mathrm{i}}\right)$ derived from the high-frequency $(1 \mathrm{~Hz})$ measurements features a strong dependence on ambient temperature. As temperature decreases from $-35^{\circ} \mathrm{C}$ to $-62{ }^{\circ} \mathrm{C}$, the peak in the PDF shifts from $10-20 \mathrm{~L}^{-1}$ to $200-1000 \mathrm{~L}^{-1}$, while $N_{\mathrm{i}}$ shows a factor of 6-7 increase.

Model simulations are performed with two different ice nucleation schemes for pure ice-phase clouds. One of the schemes can reproduce a clear increase of $N_{\mathrm{i}}$ with decreasing temperature by using either an observation-based ice nuclei spectrum or a classical-theory-based spectrum with a relatively low (5-10\%) maximum freezing ratio for dust aerosols. The simulation with the other scheme, which assumes a high maximum freezing ratio $(100 \%)$, shows much weaker temperature dependence of $N_{\mathrm{i}}$. Simulations are also performed to test empirical parameters related to water vapor deposition and the autoconversion of ice crystals to snow. Results show that a value between 0.05 and 0.1 for the water vapor deposition coefficient, and $250 \mu \mathrm{m}$ for the critical diameter that distinguishes ice crystals from snow, can produce good agreement between model simulation and the SPARTICUS measurements in terms of $N_{\mathrm{i}}$ and effective radius. The
\end{abstract}

climate impact of perturbing these parameters is also discussed.

\section{Introduction}

Microphysical processes in ice- and mixed-phase clouds have significant impacts on cloud radiative properties (Smith et al., 1998; Jensen et al., 2010) and precipitation formation (Heymsfield, 1977). Compared to the understanding of processes in warm clouds, our knowledge about ice particle formation and transformation is still very limited (Kärcher and Spichtinger, 2009). In particular, details of the homogeneous and heterogeneous nucleation processes under various atmospheric conditions, as well as their relative contributions to the formation of ice crystals in cold clouds, remain unclear (Sassen and Dodd, 1988; Detwiler, 1989; Jensen et al., 1998; DeMott et al., 2003; Cziczo et al., 2004; Prenni et al., 2007; Spichtinger and Gierens, 2009). The interactions among various cloud microphysical and macrophysical processes further complicate the situation, which results in large uncertainties in the parameterization of ice- and mixed-phase clouds in global climate models (GCM) (Mitchell et al., 2008; Kärcher and Burkhardt, 2008; Lohmann and Hoose, 2009; Gettelman et al., 2010; Salzmann et al., 2010; Wang and Penner, 2010; Yun and Penner, 2012).

There are a number of empirical parameters in ice parameterization schemes in current GCMs and in cloud parcel models that are used to develop such parameterizations. For example, a parameter $f_{\max }$ is commonly used in 
classical-theory-based heterogeneous ice nucleation schemes (e.g., Barahona and Nenes, 2009b; Hoose et al., 2010) to set an upper limit on the freezing fraction of the potential ice nuclei population. A larger $f_{\max }$ can result in larger contribution from heterogeneous ice nucleation at warmer temperatures and potentially inhibit the homogeneous nucleation. For mineral dust particles (which are efficient ice nuclei), Liu et al. (2007) and Hoose et al. (2010) assumed the maximum ice-nucleating fraction (a concept very similar to $f_{\max }$ ) to be $100 \%$ for immersion freezing, while Barahona and Nenes (2009b) used a $f_{\max }$ value of $5 \%$. Another example of uncertain parameters is the deposition coefficient $\alpha$ (also called the mass accommodation coefficient) of water vapor on ice, which determines the diffusional growth efficiency of ice crystals. As pointed out by Skrotzki et al. (2012), this parameter has not been well constrained by laboratory experiments, with values obtained by different research groups spanning about three orders of magnitude (e.g., Table 1 in Skrotzki et al., 2012, Table 5.5 in Pruppacher and Klett, 1997, and Table 4 in this paper). Magee et al. (2006) inferred from laboratory measurements a most likely range of 0.0045 to 0.0075 for ice particle growing at $-50{ }^{\circ} \mathrm{C}$, while recent cloud chamber experiments of Skrotzki et al. (2012) suggested a value of $0.6 \pm 0.4$ rather independent to temperature in the wide range between $190 \mathrm{~K}$ and $235 \mathrm{~K}$. The reason for the discrepancies is not yet clear (Skrotzki et al., 2012). In numerical models, different values between 0.04 and 1 have been used. Lin et al. (2002) pointed out that the simulated total number of nucleated ice crystals is very sensitive to $\alpha$ in seven parcel models. A similar finding was reported by Lohmann et al. (2008) using the ECHAM5 GCM. These sensitivities and discrepancies suggest that observational data are urgently needed to constrain empirical parameters in GCMs.

There are currently two types of observational data available for ice crystal microphysical properties: direct measurements (e.g., Krämer et al., 2009; Lawson, 2011), and remotesensing data from satellites and/or ground-based instruments (e.g., Mace et al., 2005; Deng and Mace, 2006, 2008). For the purpose of quantitative comparison with model simulations, remote-sensing data need to be used with care because the quantities they provide strongly depend on the shapes and habits of ice particles assumed by the retrieval algorithms. These assumptions may not be consistent with those used in GCMs, and thus can cause difficulties in interpreting the comparison results unless a proper simulator is used. In contrast, direct measurements are more straightforward to use and meanwhile can provide concurrent data for various quantities at high frequency. Aircraft in situ observations are a good source of direct measurements, especially for high altitudes. The main limitation is the relatively small spatial and temporal coverage, with flights through cirrus clouds being even rarer. Another commonly encountered issue is that when ambient air is taken into airborne instruments, large crystals can shatter on the probe tips or the inlet shroud, consequently producing biases in the measured $N_{\mathrm{i}}$ and size

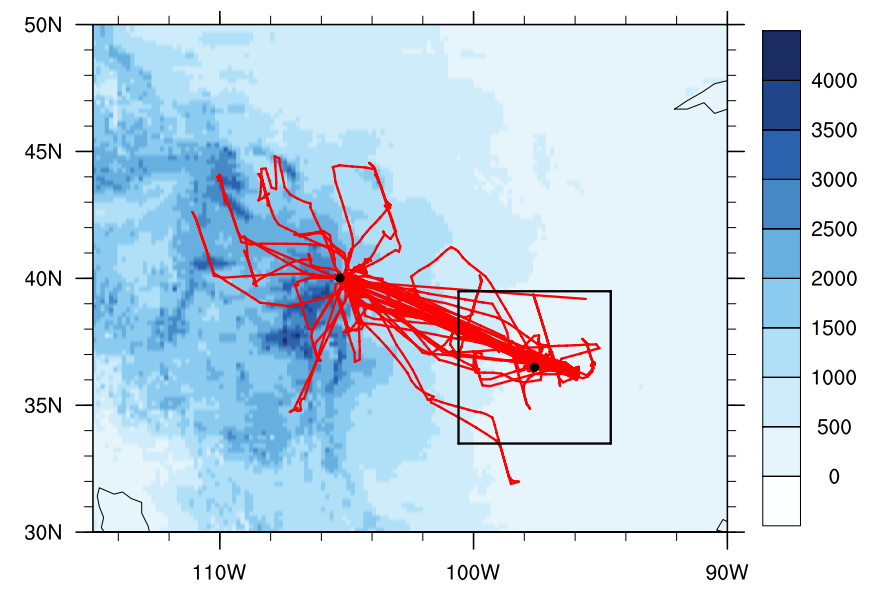

Fig. 1. Aircraft trajectories during the SPARTICUS field campaign. Color shading shows the surface elevation (unit: $\mathrm{m}$ ). The black dot at $40^{\circ} \mathrm{N}$ indicates the location of Boulder, $\mathrm{CO}$. The square indicates a $6^{\circ} \times 6^{\circ}$ (about $600 \mathrm{~km} \times 600 \mathrm{~km}$ ) area centered at the ARM SGP site $\left(36^{\circ} \mathrm{N}, 97^{\circ} \mathrm{W}\right)$, within which the $N_{\mathrm{i}}$ measurements are used for model evaluation in this paper. Further details can be found in Sect. 2

distribution (Gardiner and Hallett, 1985; Field et al., 2003, 2006a; McFarquhar et al., 2007; Jensen et al., 2009; Krämer et al., 2009).

During the SPARTICUS (Small PARTicles In CirrUS) campaign (http://acrf-campaign.arm.gov/sparticus/), about $200 \mathrm{~h}$ of data were collected from January to June 2010 between Boulder, CO, and the Southern Great Plain (SGP) site of the Atmospheric Radiation Measurement (ARM) Program (Fig. 1). New two-dimensional stereo-imaging probes (2D-S) and improved algorithms designed by Lawson et al. (2006) and Lawson (2011) were employed to reduce possible biases in the measured $N_{\mathrm{i}}$ resulting from the shattering of ice crystals on airborne instrument inlets. During the SPARTICUS campaign, $N_{\mathrm{i}}$ and size distribution as well as ambient meteorological variables were measured concurrently, providing valuable references for model development and evaluation.

In this work we use measurements from the SPARTICUS campaign to evaluate two ice cloud parameterization schemes (cf. Sect. 3.2) in a global climate model and to constrain three empirical parameters: the maximum freezing fraction $f_{\max }$ of dust aerosols, the deposition coefficient of water vapor on ice crystals $(\alpha)$, and the critical diameter $D_{\mathrm{cs}}$ that distinguishes cloud ice and snow as two classes of icephase hydrometeors (cf. Sect. 4). We focus on the number concentration and size of ice crystals as well as their relationship with temperature because the concentration and effective radius of condensates are the factors that determine the radiative properties of clouds and hence their impact on climate. Given that most of the measurements during SPARTICUS were collected in synoptic cirrus clouds, we concentrate on this cloud type in the present paper, and do not consider the topic of droplet freezing in mixed-phase clouds. 
Table 1. Number of measurement samples obtained inside and outside synoptic cirrus clouds during the SPARTICUS campaign in a $600 \mathrm{~km} \times 600 \mathrm{~km}$ area centered at the ARM SGP site (cf. Fig. 1). When $N_{\mathrm{i}}$ is larger than $0.01 \mathrm{~L}^{-1}$, it is considered as inside cirrus.

\begin{tabular}{lcc}
\hline Temperature range & Inside cirrus & Outside cirrus \\
\hline $205 \mathrm{~K}-215 \mathrm{~K}$ & 11926 & 9719 \\
$215 \mathrm{~K}-225 \mathrm{~K}$ & 32627 & 26076 \\
$225 \mathrm{~K}-235 \mathrm{~K}$ & 35935 & 23957 \\
$235 \mathrm{~K}-245 \mathrm{~K}$ & 18480 & 15719 \\
\hline
\end{tabular}

Discussion on detrainment of ice crystals from convective clouds is also excluded from this work because the number of flights with anvil occurrence is small in this campaign.

The remainder of the paper is organized as follows: Sect. 2 provides further details about the SPARTICUS aircraft measurements used in this study. Sections 3 and 4 summarize the ice cloud parameterization schemes in CAM5 and describe the simulations performed in this study. Results are shown and discussed in Sect. 5. Conclusions are drawn in Sect. 6.

\section{SPARTICUS aircraft measurements}

During the SPARTICUS field campaign, a SPEC Learjet aircraft collected about $200 \mathrm{~h}$ of in situ microphysics observations from January to June 2010 along trajectories between Boulder, $\mathrm{CO}\left(40^{\circ} \mathrm{N}, 105^{\circ} \mathrm{W}\right)$, and the ARM SGP site $\left(36^{\circ} \mathrm{N}\right.$, $97^{\circ} \mathrm{W}$, Fig. 1). Number concentration and size distribution of ice crystals that have a maximum dimension $D_{\max }$ between $10 \mu \mathrm{m}$ and $3000 \mu \mathrm{m}$ were measured by a $2 \mathrm{D}-\mathrm{S}$ probe. The probe generates two orthogonal laser beams to create twodimensional silhouettes of ice particles larger than $10 \mu \mathrm{m}$. Compared to conventional optical array probes (Knollenberg, 1970), the stereo view of particles in the laser-beam overlap region improves the sample volume boundaries and sizing of small $(<100 \mu \mathrm{m})$ particles. With improved probe tip design and particle interarrival time algorithms, the 2D$S$ probe can also reduce the shattering of ice particles and provide reliable $N_{\mathrm{i}}$ measurements (Lawson, 2011). As small ice crystals $\left(10 \mu \mathrm{m}<D_{\max }<100 \mu \mathrm{m}\right)$ dominate the ice particle population in cirrus clouds, the better measurement accuracy of $2 \mathrm{D}-\mathrm{S}$ in this size range provides reliable data to evaluate the numerical model. Ambient temperatures were measured by the Rosemount probe (Model 102, precision: $\pm 0.5^{\circ} \mathrm{C}$ ). An open path diode laser hygrometer (DLH) (precision: $\pm 1 \%$ ) was employed to measure the water vapor mixing ratio, which operates in the near-infrared spectral region ((Diskin et al., 2002)). In order to be consistent with the model calculation of relative humidity with respect to ice $\left(\mathrm{RH}_{\mathrm{i}}\right)$, observation-derived $\mathrm{RH}_{\mathrm{i}}$ is calculated based on Goff and Gratch (1946) using water vapor mixing ratio, ambient pressure, and temperature. The effective diameter of ice crystals is derived from the observed crystal size distribution following Mitchell (2002). The observational data are available at the frequency of 1 record per second. Considering the speed of the aircraft, this frequency translates to a horizontal distance of 150-200 m between two individual measurement records of ice crystal distribution, temperature, $\mathrm{RH}_{\mathrm{i}}$, etc.

The aircraft trajectories covered various types of topography in this campaign, from the Rocky Mountains in the west to the relatively homogeneous geography over the Southern Great Plains (SGP) in the east (Fig. 1). In order to exclude possible biases in the model that are associated with the dynamical effects of complex topography, we do not use the whole dataset from SPARTICUS but limit the model evaluation within a $6^{\circ} \times 6^{\circ}($ about $600 \mathrm{~km} \times 600 \mathrm{~km})$ area centered at the SGP site (black square in Fig. 1). In the campaign log and pilot notes, anvil occurrence was reported when a cirrus cloud attached to a deep convective system was observed during a flight. Such flights are excluded from our analysis since the focus here is on the role of ice nucleation in synoptic cirrus clouds. This still leaves us with more than 98000 in-cirrus records of ice crystal distribution and $\mathrm{RH}_{\mathrm{i}}$, etc., with more than 10000 records in each of the $10 \mathrm{~K}$ temperature bins shown in Table 1. The large number of samples provide a solid basis for the statistical analysis of the ice crystal properties in Sect. 5.

\section{Model}

\subsection{CAM5 model}

The GCM used in this study is the Community Atmosphere Model version 5 (CAM5, Neale et al., 2010). The model uses finite volume methods in its dynamical core and tracer transport algorithm, with a standard horizontal resolution of $1.9^{\circ} \times 2.5^{\circ}$ (latitude by longitude) and a time step of $30 \mathrm{~min}$. Large-scale condensation, cloud fraction calculation, and the horizontal and vertical overlapping of clouds are handled by a cloud macrophysics parameterization of Park et al. (2012). Stratiform microphysical processes are represented by a twomoment scheme that solves prognostic equations for cloud droplet and cloud ice, and diagnostic equations for rain and snow (Morrison and Gettelman, 2008; Gettelman et al., 2008, 2010). As atmospheric aerosols play a key role in supplying cloud condensation nuclei and ice nuclei (IN), a modal aerosol module (MAM, Liu et al., 2012a) is incorporated to interactively predict mass and number concentrations of various aerosol species including sulfate, sea salt, primary and secondary organic matter, black carbon, and dust. Among these species, dust particles can act as ice nuclei. Ice particles can also form through the homogeneous freezing of aqueous sulfate solution droplet. The size distribution of aerosol particles is described by either three or seven log-normal modes. In this study we use the three-mode version MAM3, which consists of the Aitken, accumulation, and coarse modes. Dust in the accumulation and coarse modes participates in 
Table 2. Ice formation mechanisms considered in the CAM5 model (version CAM5_0_40) and the ambient conditions under which they can take effect. $q_{1}$ and $N\left(D_{\mathrm{p}}\right)$ denote the mass mixing ratio and size distribution function of cloud droplets, respectively. $T_{\mathrm{m}}$ (unit: ${ }^{\circ} \mathrm{C}$ ) is the equivalent temperature defined in Liu and Penner (2005, $\mathrm{LP} 05) . \mathrm{RH}_{\mathrm{w}}^{\mathrm{cr}}$ denotes the critical relative humidity with respect to water for homogeneous nucleation.

\begin{tabular}{|c|c|c|c|}
\hline Mechanisms & Condition & Initial crystal size & Reference \\
\hline Ice formation in pure ice-phase clouds & $\begin{array}{l}-37^{\circ} \mathrm{C}<T<0{ }^{\circ} \mathrm{C} \text { and } q_{1}=0, \\
\text { or } T<-37^{\circ} \mathrm{C}\end{array}$ & & \\
\hline Option 1: LP05 scheme & & & Liu and Penner (2005) \\
\hline Homogeneous nucleation & $T<T_{\mathrm{m}}-5, \mathrm{RH}_{\mathrm{W}}>\mathrm{RH}_{\mathrm{w}}^{\mathrm{cr}}$ & $10 \mu \mathrm{m}$ & \\
\hline Heterogeneous nucleation & $T_{\mathrm{m}}<T<0{ }^{\circ} \mathrm{C}, \mathrm{RH}_{\mathrm{i}}>120 \%$ & $10 \mu \mathrm{m}$ & \\
\hline Transition (Hom/Het) nucleation & $T_{\mathrm{m}}-5<T<T_{\mathrm{m}}, \mathrm{RH}_{\mathrm{i}}>120 \%$ & $10 \mu \mathrm{m}$ & \\
\hline Option 2: BN09 scheme & & & Barahona and Nenes $(2008,2009 b)$ \\
\hline Homogeneous nucleation & $T<-37^{\circ} \mathrm{C}, \mathrm{RH}_{\mathrm{W}}>\mathrm{RH}_{\mathrm{w}}^{\mathrm{cr}}$ & $10 \mu \mathrm{m}$ & \\
\hline Heterogeneous nucleation & $T<0^{\circ} \mathrm{C}, \mathrm{RH}_{\mathrm{i}}>120 \%$ & $10 \mu \mathrm{m}$ & \\
\hline Ice formation in mixed-phase clouds & $q_{1}>0$ and $T<0{ }^{\circ} \mathrm{C}$ & & \\
\hline Contact freezing & $T<-4{ }^{\circ} \mathrm{C}$ & Dependent on $N\left(D_{\mathrm{p}}\right)$ & Young (1974) \\
\hline Deposition/condensation freezing & $-37^{\circ} \mathrm{C}<T<0{ }^{\circ} \mathrm{C}$ & $10 \mu \mathrm{m}$ & Meyers et al. (1992) \\
\hline Homogeneous freezing of cloud droplets & $T<-40{ }^{\circ} \mathrm{C}$ & $25 \mu \mathrm{m}$ & \\
\hline \multicolumn{4}{|l|}{ Detrainment from convective clouds } \\
\hline Shallow convection & $T<-5^{\circ} \mathrm{C}$ & $50 \mu \mathrm{m}$ & Neale et al. (2010) \\
\hline Deep convection & $T<-5^{\circ} \mathrm{C}$ & $25 \mu \mathrm{m}$ & \\
\hline
\end{tabular}

heterogeneous ice nucleation; sulfate in the Aitken mode is allowed to participate in the homogeneous nucleation. Moist turbulence and shallow convection are parameterized by the schemes of Bretherton and Park (2009) and Park and Bretherton (2009), respectively. Deep convection is treated with the parameterization of Zhang and McFarlane (1995) with further modifications by Richter and Rasch (2008). Shortwave and longwave radiative transfer calculations are performed using the RRTMG code (Iacono et al., 2008; Mlawer et al., 1997). Details of the model formulation are described by Neale et al. (2010).

\subsection{Ice nucleation}

The formation of ice crystals in stratiform clouds considered in CAM5 includes ice nucleation in cirrus (i.e., pure ice phase) clouds, droplet freezing in mixed-phase clouds, and detrainment of ice crystals from convective clouds formed by either shallow or deep convection. Table 2 summarizes the ambient conditions under which these mechanisms can take effect. In this study we focus on ice nucleation in cirrus clouds.

The ice nucleation scheme used in CAM5 originated from the parameterization of Liu et al. (2007). It was derived as an empirical fit of a parcel model simulation performed by Liu and Penner (2005, hereafter LP05) in which the nucleation rates were calculated with the classical nucleation theory. Based on the work of Liu et al. (2007), Gettelman et al. (2010) coupled LP05 with the Morrison and Gettelman (2008) stratiform cloud microphysics and the aerosol module MAM of Liu et al. (2012a). It has also adopted the cloud macrophysics closure proposed by
Park et al. (2012), and it allows supersaturation with respect to ice. Despite these changes, crystal formation in pure icephase clouds stays the same as in Liu et al. (2007), i.e., the empirical fit of results from LP05. It is worth noting that the parcel model simulation in LP05 was performed with a set of prescribed parameters (e.g., the water vapor deposition coefficient). The empirical fit was implemented in the CAM5 model as a lookup table. If one intended to carry out CAM5 simulations with different values for these parameters, it would be necessary to rerun the parcel model and rederive the lookup table. This severely limits the flexibility of the LP05 ice nucleation parameterization.

Recently Liu et al. (2012b) implemented in CAM5 a physically based parameterization for the ice nucleation in cirrus clouds, originally proposed by Barahona and Nenes (2008) and later extended by Barahona and Nenes (2009a,b, hereafter BN09). The BN09 parameterization explicitly considers effects of water vapor deposition on simulated $N_{\mathrm{i}}$. It also provides the flexibility of using different IN spectra (with respect to ambient conditions) for the heterogeneous nucleation calculation. The default configuration uses an empirical spectrum derived from observation (Phillips et al., 2008). Optionally, one can choose to use spectra derived from classical nucleation theory (Barahona and Nenes, 2009b). Furthermore, the scheme can be extended to consider the effect of preexisting ice crystals on ice nucleation (D. Barahona, personal communication, 2012). The BN09 scheme provides a flexible basis for investigating the uncertainties associated with empirical parameters.

For cirrus clouds, both the LP05 and BN09 schemes include homogeneous nucleation on sulfate, heterogeneous 
Table 3. List of sensitivity experiments presented in this study.

\begin{tabular}{|c|c|}
\hline Experiment name & Purpose and configuration \\
\hline Group A: & Sensitivity to nucleation scheme for cirrus clouds \\
\hline LP & $\begin{array}{l}\text { Liu and Penner (2005) scheme for ice nucleation in cirrus cloud, freezing of droplets in } \\
\text { mixed phase clouds considered. With deposition coefficient of } \alpha=0.1 \text { and } D_{\mathrm{cs}}=400 \mu \mathrm{m} \text {. }\end{array}$ \\
\hline LPHET & As in LP, but only with heterogeneous nucleation in cirrus clouds. \\
\hline LPHOM & As in LP, but only with homogeneous nucleation in cirrus clouds. \\
\hline $\mathrm{BN}$ & $\begin{array}{l}\text { Barahona and Nenes (2009b) scheme for ice nucleation in cirrus cloud, IN spectra follows } \\
\text { Philips et al. (2008), with deposition coefficient of } \alpha=0.1 \text { and } D_{\mathrm{cs}}=400 \mu \mathrm{m} \text {. }\end{array}$ \\
\hline BNHET & As in $\mathrm{BN}$, but only with heterogeneous nucleation in cirrus clouds. \\
\hline BNHOM & As in $\mathrm{BN}$, but only with homogeneous nucleation in cirrus clouds. \\
\hline Group B: & Sensitivity to the maximum freezing ratio of the potential ice nuclei population $\left(f_{\max }\right)$ \\
\hline BNCNT & $\begin{array}{l}\text { As in BN in Group A, but uses a classical-nucleation-theory (CNT)-based IN spectra for } \\
\text { heterogeneous nucleation in the ice phase. The contact angle for dust ice nuclei is } 16^{\circ} \text { (Chen } \\
\text { et al., 2008). With } \alpha=0.1, D_{\mathrm{cs}}=400 \mu \mathrm{m} \text {, and } f_{\max }=5 \% \text {. }\end{array}$ \\
\hline BNCNT_F10 & As in BNCNT, but with $f_{\max }=10 \%$. \\
\hline BNCNT_F50 & As in BNCNT, but with $f_{\max }=50 \%$. \\
\hline BNCNT_F100 & As in BNCNT, but with $f_{\max }=100 \%$ \\
\hline Group C: & Sensitivity to the water vapor deposition coefficient $\alpha($ default value $=0.1)$ \\
\hline BN_ $\alpha 0.5$ & As in BN of Group A, but with $\alpha=0.5$ \\
\hline BN_ $\alpha 0.05$ & As in BN of Group A, but with $\alpha=0.05$ \\
\hline BN_ $\alpha 0.006$ & As in BN of Group A, but with $\alpha=0.006$ \\
\hline Group D: & Sensitivity to crystal/snow separating diameter $D_{\mathrm{cs}}($ default value $=400 \mu \mathrm{m})$ \\
\hline BN_Dcs 175 & As in BN of Group A, but with $D_{\mathrm{cs}}=175 \mu \mathrm{m}$ \\
\hline BN_Dcs 250 & As in BN of Group A, but with $D_{\mathrm{cs}}=250 \mu \mathrm{m}$ \\
\hline BN_Dcs325 & As in BN of Group A, but with $D_{\mathrm{cs}}=325 \mu \mathrm{m}$ \\
\hline
\end{tabular}

immersion freezing on mineral dust, as well as competition between the two mechanisms. Deposition nucleation and immersion freezing on soot are neglected in the model due to the still poor understanding of these processes (Kärcher et al., 2007). The number concentration of nucleated ice crystals is computed as a function of temperature, humidity, aerosol (sulfate and dust) number concentration, and subgrid updraft velocity. The subgrid updraft velocity is derived from the turbulent kinetic energy (TKE) calculated by the moist turbulence scheme of Bretherton and Park (2009), with an assumed maximum ${ }^{1}$ value of $0.2 \mathrm{~ms}^{-1}$.

In addition to ice nucleation in pure ice-phase clouds, cloud droplets can freeze to form ice crystals too. Deposi-

\footnotetext{
${ }^{1}$ In the literature the threshold updraft velocity for ice nucleation has been mentioned differently. The scientific description of CAM5.0 (Neale et al., 2010, p. 135) documented a minimum value of $0.2 \mathrm{~m} \mathrm{~s}^{-1}$. In the work of Gettelman et al. (2010), the baseline simulation used a minimum value of $0.2 \mathrm{~ms}^{-1}$, while the sensitivity experiment WSUB tested a maximum of $0.2 \mathrm{~ms}^{-1}$. Liu et al. (2012b, Sect. 2.3) also mentioned a maximum value of $0.2 \mathrm{~ms}^{-1}$. We have confirmed that in the standard code release of CAM5.0 and CAM5.1 (http://www.cesm.ucar.edu/models/), the threshold value for ice nucleation is set as a maximum, not a minimum.
}

tion/condensation freezing is considered in the model based on Meyers et al. (1992), with a constant freezing rate below $-20^{\circ} \mathrm{C}$. Contact freezing of cloud droplets is included based on Young (1974) using the number concentration of coarse mode dust. Homogeneous freezing of cloud droplets is assumed to occur instantaneously at $-40^{\circ} \mathrm{C}$. Ice crystals detrained from the convective clouds are distributed into the environment by assuming a mean volume radius of $50 \mu \mathrm{m}$ for shallow convection and $25 \mu \mathrm{m}$ for deep convection. More details can be found in Table 2 and references therein.

\section{Experimental design}

CAM5 simulations presented in this paper are summarized by Table 3 . The horizontal and vertical resolutions are $1.9^{\circ} \times$ $2.5^{\circ}$ (latitude $\times$ longitude) and 30 vertical levels, respectively. The model time step is $30 \mathrm{~min}$. For each simulation, we run the model for $5 \mathrm{yr}$ plus 3 months of spin-up, driven by climatological sea surface temperatures and sea ice extent. Emissions of anthropogenic aerosols and their precursors are prescribed according to Lamarque et al. (2010) using the year 2000 setup. Strictly speaking, it may not be ideal to carry 
out model evaluation by comparing a $5 \mathrm{yr}$ climatological run with measurements from a single campaign. But considering that (i) the SPARTICUS data used here have a relatively long temporal coverage ( $200 \mathrm{~h}$ spanning 6 months, in contrast to most field observations of cirrus clouds in the past that lasted only several hours or days), (ii) there were no peculiar weather conditions, extreme events or unusual aerosol concentrations (e.g., after volcanic eruptions) encountered during the flights, and (iii) the model data used in the analysis are taken from the same months of year as the measurements, we consider the evaluation presented here as a useful exercise in constraining uncertain model parameters. In the future, better evaluation strategies can be employed by using, e.g., the nudging capability that recently became available in the CAM5 model (Kooperman et al., 2012).

In order to compare model results with the SPARTICUS measurements, 3-hourly instantaneous output are obtained over the SGP area. These are used to calculate probability density functions (PDFs) of the number concentration and effective diameter of ice crystals as well as their relationship with temperature. For the purpose of (i) identifying the dominant mechanisms of ice nucleation and (ii) following the same sampling conditions as in observation, we also included in model output the tendency rates related to processes listed in Table 2.

In total we have carried out 15 simulations in 4 groups. Group A first compares the behavior of the LP05 and BN09 schemes in their default configuration, which includes the competition between homogeneous and heterogeneous nucleation (simulations LP and BN). To help understand the relative contributions of different nucleation mechanisms, two additional sensitivity tests are performed with each parameterization, with only homogeneous (LPHOM and BNHOM) or heterogeneous (LPHET and BNHET) nucleation switched on in cirrus clouds. The representation of mixedphase clouds is kept the same.

In the other three groups of simulations $(\mathrm{B}, \mathrm{C}$, and $\mathrm{D})$ we use the BN09 scheme to investigate the sensitivity of ice cloud simulations to empirical parameters. Selected values based on review of the literature are applied, and their effects evaluated by contrasting the results and comparing them with observations. Further details of the parameters and the values used in our simulations are given below.

Simulations in Group B replace the empirical IN spectrum for heterogeneous ice nucleation in the default BN09 scheme by a classical-theory-based spectrum of Barahona and Nenes (2009b). In this configuration, a prescribed parameter $f_{\max }$ (the maximum freezing fraction of the potential IN population) limits the number of ice nuclei, and thus has a direct impact on heterogeneous ice nucleation. In numerical models, the $f_{\max }$ of each aerosol type is usually prescribed according to the observed typical maximum values (Möhler et al., 2006; Field et al., 2006b; Phillips et al., 2008). For mineral dust, both Hoose et al. (2010) and LP05 assumed the maximum ice-nucleating fraction to be $100 \%$ for immersion freezing,
Table 4. Range of deposition coefficient $(\alpha)$ derived from laboratory experiment and field measurements as well as those used in cirrus parcel models and GCM parameterizations. Values for parcel models are collected from Lin et al. (2002). Values from Pruppacher and Klett (1997) are collected from their Table 5.5.

\begin{tabular}{|c|c|}
\hline \multicolumn{2}{|c|}{ Experimentally determined values } \\
\hline$\alpha$ & Reference \\
\hline 0.006 & Magee et al. (2006) \\
\hline $0.014-1.0$ & Pruppacher and Klett (1997) \\
\hline $0.031 \pm 0.001$ & Earle et al. (2010) \\
\hline $0.6 \pm 0.4$ & Skrotzki et al. (2012) \\
\hline \multicolumn{2}{|c|}{ Values used in parcel models or GCM parameterizations } \\
\hline$\alpha$ & Reference \\
\hline 0.04 & DeMott et al. (1994) and DeMott et al. (1998) \\
\hline 0.1 & $\begin{array}{l}\text { Lin (1997); Liu and Seidl (1998); Liu and Penner (2005), } \\
\text { Barahona and Nenes (2008) }\end{array}$ \\
\hline 0.24 & Spice et al. (1999) \\
\hline 0.36 & Sassen and Dodd (1988) and Khvorostyanov and Sassen (1998) \\
\hline 0.5 & Kärcher and Lohmann (2002) \\
\hline 1.0 & Jensen and Toon (1994) and Tabazadeh et al. (2000) \\
\hline
\end{tabular}

while the BN09 parameterization uses the value $5 \%$. In simulation Group B, three additional values $(10 \%, 50 \%$ and $100 \%)$ are tested.

Simulations in Group C investigate the impact of the water vapor deposition coefficient $\alpha$. Earlier studies (e.g., Lin et al., 2002; Comstock et al., 2008; Lohmann et al., 2008) have shown that the model-predicted $N_{\mathrm{i}}$ can be very sensitive to this coefficient. This is because ice nucleation and crystal growth compete for the available water vapor in the atmosphere. A smaller (larger) deposition coefficient will lead to a longer (shorter) period during which the relative humidity stays near the critical value for nucleation, and consequently higher (lower) concentrations of the nucleated ice crystals (Gierens, 2003). The default value in the BN09 parameterization is $\alpha=0.1$, while other models and schemes used various values between 0.04 and 1 (cf. Table 4). In simulation Group $\mathrm{C}$, we test three values $(\alpha=0.006,0.05,0.5)$ that span two orders of magnitude, and compare the results with the reference BN simulation.

In the bulk cloud microphysical schemes of Morrison and Gettelman (2008), a critical particle diameter $D_{\mathrm{cs}}$ is defined to distinguish cloud ice and snow as two different classes of solid-phase condensates. The so-called autoconversion rate, i.e., the rate at which ice crystals are converted into snow, is calculated in CAM5 by integrating the cloud ice size distribution over the range $\left[D_{\mathrm{cs}}, \infty\right]$ and transferring the resulting condensate to the snow category (Ferrier, 1994; Morrison and Gettelman, 2008). Gettelman et al. (2010) found that the separating size $D_{\mathrm{cs}}$ has a strong impact on the simulated ice water path and total cloud forcing. Various $D_{\mathrm{cs}}$ values have been used in recent versions of the CAM5 model (cf. Table 5) to achieve the top-of-atmosphere radiative balance in long-term climate simulations, although such tuning may cause biases in the simulated microphysical processes and 
Table 5. Values of $D_{\mathrm{cs}}$ (unit: $\mu \mathrm{m}$ ) in different versions of the CAM5 model. $D_{\mathrm{cs}}$ is the prescribed separating size that distinguishes cloud ice and snow as two different classes of solid-phase condensates.

\begin{tabular}{ll}
\hline$D_{\text {cs }}(\mu \mathrm{m})$ & Reference \\
\hline 200 & Morrison and Gettelman (2008) \\
250 & Gettelman et al. (2010) \\
325 & CAM5.0, Neale et al. (2010) \\
400 & CAM5.1, http://www.cesm.ucar.edu/models/cesm1.0/cam/ \\
\hline
\end{tabular}

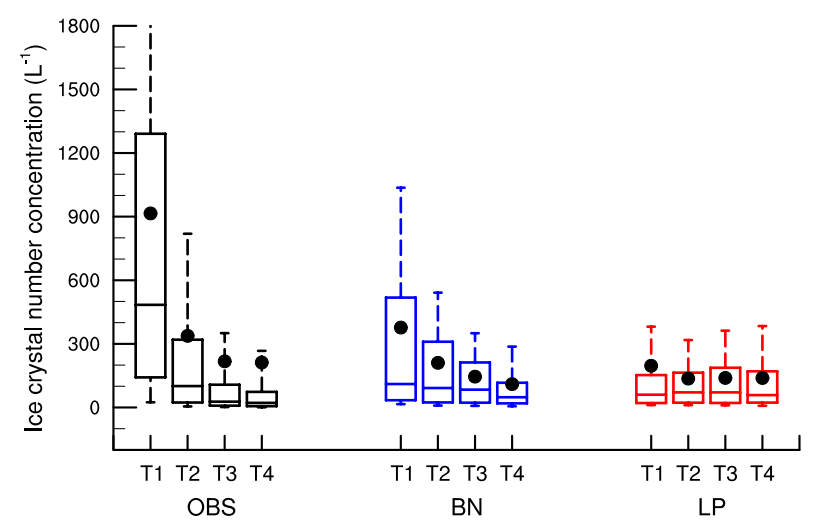

Fig. 2. Box plots showing the observed (OBS) and simulated (BN and LP) in-cirrus $N_{\mathrm{i}}$ (unit: $\mathrm{L}^{-1}$ ) in the upper troposphere (above $500 \mathrm{hPa}$ ) over the SGP area. T1, T2, T3, and T4 stand for different temperature ranges (T1: 205-215 K, T2: 215-225 K, T3: 225$235 \mathrm{~K}, \mathrm{~T} 4: 235-245 \mathrm{~K})$. LP and BN refer to simulations performed with different ice nucleation parameterizations for cirrus clouds (Table 3, Group A). The two whiskers of each box denote the 10th (lower) and 90th (upper) percentiles. Hinges from bottom to top are the 25 th, 50th, and 75th percentiles, respectively. Black dots denote the mean values. The observed 90th percentile in the T1 (205$215 \mathrm{~K}$ ) temperature range is $1981 \mathrm{~L}^{-1}$, which goes off the chart.

ice crystal size in the atmosphere. In Group D of our simulations, four different values of $D_{\mathrm{cs}}(400 \mu \mathrm{m}, 325 \mu \mathrm{m}, 250 \mu \mathrm{m}$ and $175 \mu \mathrm{m})$ are evaluated.

\section{Results}

\subsection{LP05 versus BN09 scheme}

In the literature, the LP and BN parameterizations have been compared in box model calculations by Barahona and Nenes (2008). Liu et al. (2012b) implemented the BN scheme in CAM5 and compared it with the LP scheme in global simulations by investigating the role of dust ice nuclei on the simulated model climate. Gettelman et al. (2012) also compared the two schemes in CAM5, focusing on ice nucleation and the radiative effects of anthropogenic aerosols on cirrus from a global perspective. In this paper we look specifically into the SGP region and concentrate on parameter-induced sensitivities.
$N_{\mathrm{i}}$ in the SGP area measured during the SPARTICUS campaign and simulated with the LP05 and BN09 ice nucleation schemes are presented in Fig. 2 for four temperature ranges. The numbers given here are in-cirrus values in the upper troposphere (above $500 \mathrm{hPa}$ ). In the SPARTICUS data, both the mean and median concentrations feature a marked increase with decreasing temperature (Fig. 2a). Such a feature is also seen in the NASA Mid-latitude Airborne Cirrus Properties Experiment (MACPEX, cf. Appendix A). Consistently, the PDF of $N_{\mathrm{i}}$ shown in Fig. 3a for the SPARTICUS measurements features a clear shift of the peak from $10-20 \mathrm{~L}^{-1}$ at $-35^{\circ} \mathrm{C}$ to $200-1000 \mathrm{~L}^{-1}$ at temperatures below $-60^{\circ} \mathrm{C}$. The BN09 scheme can reproduce an increase of the mean $N_{\mathrm{i}}$ with decreasing temperature (Fig. 2b), although not as strong as in the observation, while the LP09 scheme gives rather constant

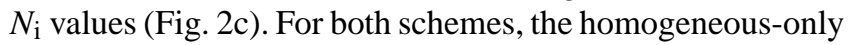
simulations feature a shift of the $N_{\mathrm{i}}$ PDF towards higher concentrations at lower temperature, while the heterogeneousonly simulations does not show this trend (Fig. 3). The temperature dependence of $N_{\mathrm{i}} \mathrm{PDF}$ in the default BN simulation (Fig. 3b) looks very similar to BNHOM (homogeneous only, Fig. 3c). The default LP run (Fig. 3e), in contrast, appears more similar to the corresponding heterogeneous-only simulation (Fig. 3g). This suggests that the relative contributions of the two nucleation mechanisms are different in LP and $\mathrm{BN}$.

To provide more quantitative evidence for this statement, the upper panel in Fig. 4 shows a breakdown of the ice crystal number production rate (i.e., the number of newly produced ice crystals per liter per model time step) at $200 \mathrm{hPa}$ in the SGP area, in the default LP and BN simulations. While homogeneous and heterogeneous nucleation play similar roles in crystal number production in LP, the BN simulation is dominated by homogeneous nucleation. In the lower panel of the same figure, the nucleation frequency - defined as the number of occurrence of (homogeneous or heterogeneous) nucleation event divided by the total number of model time steps - is compared between the two schemes. The lower panel of Fig. 4 shows similar heterogeneous nucleation frequencies in the two simulations, but a factor of 10 difference in the homogeneous nucleation frequency. The same analyses have been repeated for other pressure levels in the upper troposphere and led to similar results (not shown). Figure 4 thus confirms that $N_{\mathrm{i}}$ simulated using the default BN scheme are dominated by homogeneous nucleation, while the heterogeneous nucleation plays a much more important role in the LP simulation. Furthermore, we note that this difference is not only seen in the SGP area but also generally present in most other regions in the Northern Hemisphere $(\mathrm{NH})$, as can be seen in Fig. 5, where the $200 \mathrm{hPa}$ zonal averages are shown for several quantities. Consistent with Fig. 4, in the LP05 simulation the contribution of heterogeneous nucleation to total $N_{\mathrm{i}}$ production is much larger than in BN09 (Fig. 5a, blue vs. red curve). The homogeneous nucleation happens considerably less often in LP05 than in 

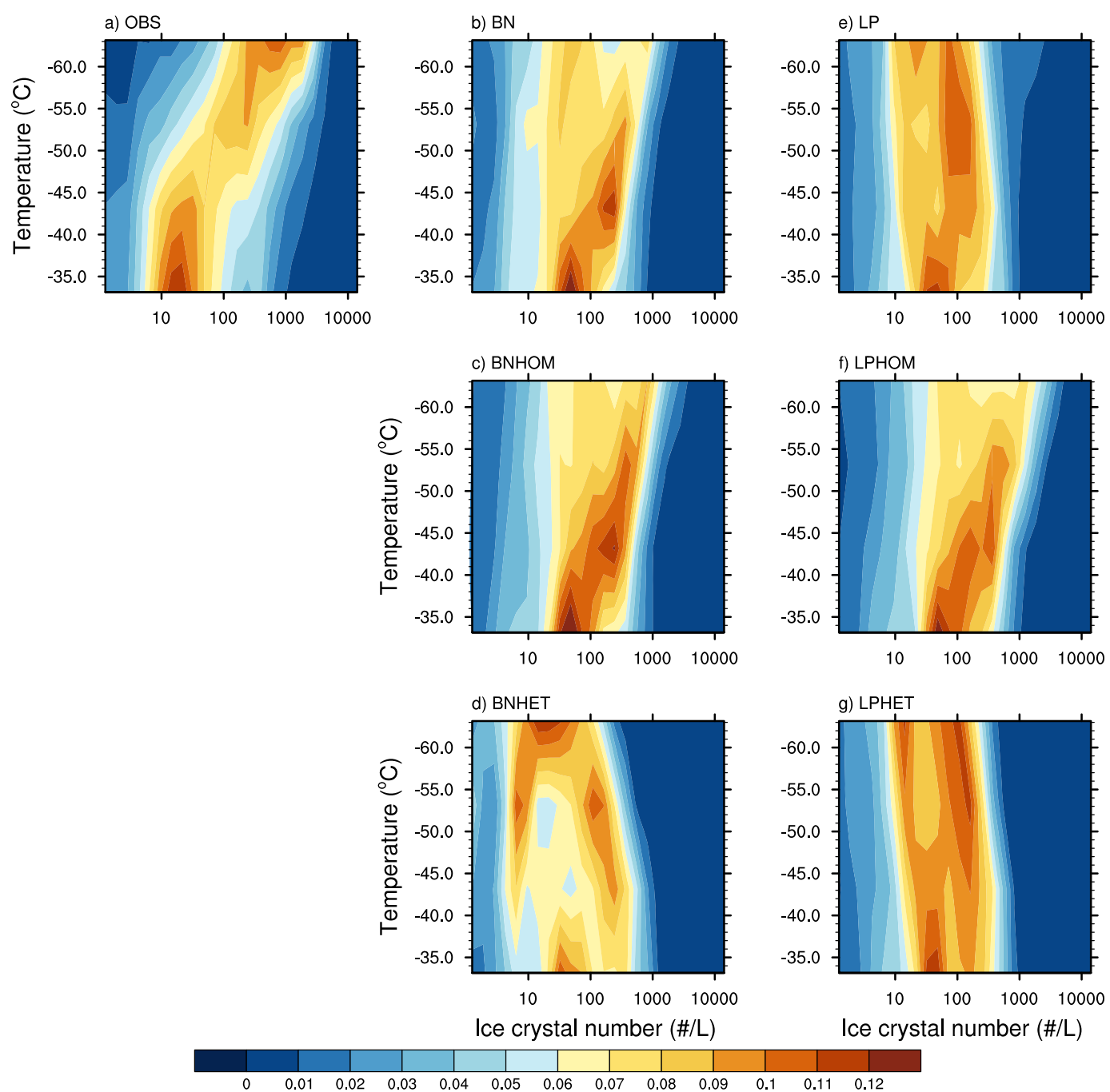

Fig. 3. Observed and simulated probability density function (PDF) of $N_{\mathrm{i}}$ in cirrus clouds in the upper troposphere (above $500 \mathrm{hPa}$ ) at different ambient temperatures. The observed PDF is derived from $1 \mathrm{~Hz}$ measurements in the SGP area obtained during the SPARTICUS campaign. The simulated PDFs are computed from $5 \mathrm{yr}$ of instantaneous 3-hourly model output in the months and locations of the measurements.

BN09 (Fig. 5b, blue curve). In Fig. 5c, d, the zonally and annually averaged in-cloud $N_{\mathrm{i}}$ are shown for all simulations in Group A. The BN09 simulations with and without heterogeneous nucleation give rather similar results (panel b), while the homogeneous-only LP05 simulation features considerably higher $N_{\mathrm{i}}$ than the default configuration (panel a).

In the model, sufficiently high relative humidity with respect to ice $\left(\mathrm{RH}_{\mathrm{i}}\right)$ is one of the key conditions for ice nucleation to occur (cf. Table 2). To check whether this is the cause of the differences between the LP and $\mathrm{BN}$ simulations, Fig. 6 compares the simulated and observed bivariate PDF of $\mathrm{RH}_{\mathrm{i}}$ and ambient temperature in different cases distinguished by the ice crystal number concentration. The clear-sky cases (Fig. 6, left column) are also included here to take into account the initial stage of cirrus formation. Following Haag et al. (2003), $\mathrm{RH}_{\mathrm{i}}$ values higher than water saturation are not included in the analysis. In CAM5, $\mathrm{RH}_{\mathrm{i}}$ diagnosed in different parts of the time integration procedure can have different values due to the time splitting algorithm. The values we present here are those used in the ice nucleation calculation.

The SPARTICUS data clearly reveal lower $\mathrm{RH}_{\mathrm{i}}$ in clear sky than inside cirrus (Fig. 6a versus b), although high ice supersaturation $(>120 \%)$ can happen in both cases. Such high ice supersaturation over the SGP area has already been reported before (Comstock et al., 2004). Both inside and outside cirrus, higher $\mathrm{RH}_{\mathrm{i}}$ values are observed at lower temperatures. This is in agreement with earlier studies by Ovarlez et al. (2002) and Spichtinger et al. (2004), where it was shown that the shape of the in-cloud humidity PDF changes from nearly symmetric around ice saturation in relatively warm cirrus to considerably positively skewed in colder clouds. Inside cirrus clouds, cases with higher $N_{\mathrm{i}}$ (Fig. 6d) 


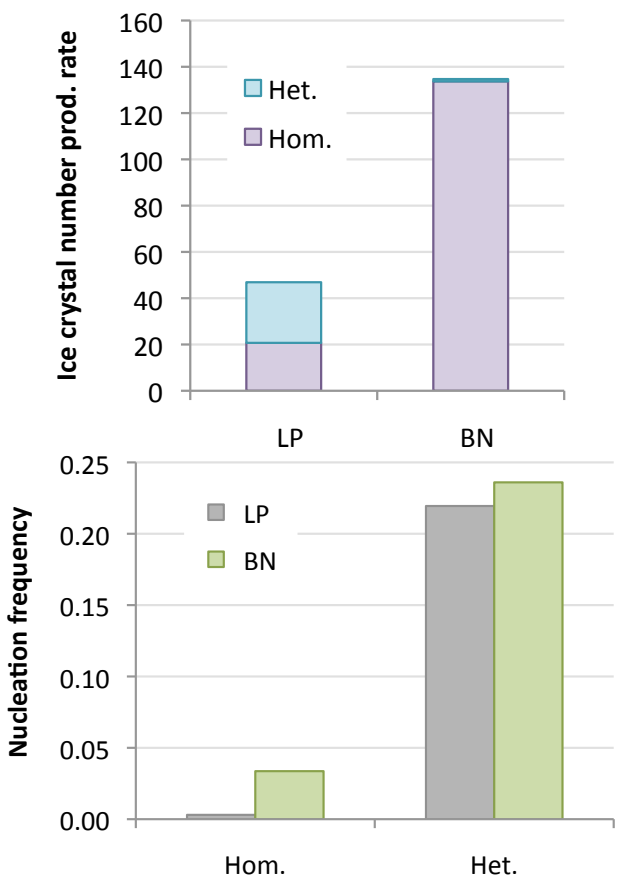

Fig. 4. Upper panel: contributions of heterogeneous and homogeneous ice nucleation to crystal production at $200 \mathrm{hPa}$ over the SGP area in CAM5 simulations performed with the default LP05 and BN09 parameterization schemes (cf. Table 3, Group A). The production rates are given in the unit of number of crystals per liter per model time step (i.e., $30 \mathrm{~min}$ ). Lower panel: the frequency of occurrence of the two nucleation mechanisms in different simulations.

are more often associated with lower temperature and higher humidity (e.g., $T \leq-50^{\circ} \mathrm{C}, \mathrm{RH}_{\mathrm{i}} \geq 130 \%$ ) than the cases with lower $N_{\mathrm{i}}$ (Fig. 6c).

In a qualitative sense, these features are captured by the model to some extent, despite a general underestimation of supersaturation (Fig. 6 second and third rows). In the model, the air is ice-supersaturated about $33 \%$ of the time inside cirrus clouds, significantly lower than the observed percentage $(56 \%)$ during SPARTICUS. Below $-45^{\circ} \mathrm{C}$, the simulated peaks of the in-cloud $\mathrm{RH}_{\mathrm{i}} \mathrm{PDF}$ appear persistently around ice-saturation, rather than shift towards higher values as temperature decreases. These biases are not unexpected given the rather coarse spatial and temporal resolutions of global climate models, as well as the lack of realistic representation of subgrid variability (e.g., Kärcher and Burkhardt, 2008; Wang and Penner, 2010). As a primitive remedy, the current CAM5 assumes that the "most humid portion" of a grid box has an $\mathrm{RH}_{\mathrm{i}}$ value $20 \%$ higher than the grid-box mean (Gettelman et al., 2010; Neale et al., 2010). This means the heterogeneous nucleation can be triggered at $\mathrm{RH}_{\mathrm{i}}=100 \%$ (grid-box mean value) when ice nuclei are available.

Regardless of the discrepancies between observation and model simulation, we can see from Fig. 6 that the relative humidity in the LP and BN simulations is very similar. Therefore, the $\mathrm{RH}_{\mathrm{i}}$ cannot explain the different ice nucleation fre- quencies in the two simulations. We have also checked other conditions that directly affect ice nucleation in the model, e.g., subgrid updraft velocity and number concentration of sulfate and dust particles. They appear to be also rather similar between the two simulations.

\subsection{Sensitivity to $f_{\max }$}

In the previous subsection, the $\mathrm{LP}$ and $\mathrm{BN}$ simulations are performed with the default configuration of the corresponding ice nucleation scheme, i.e., using a classical-nucleationtheory (CNT)-based IN spectrum for heterogeneous nucleation in LP and an observation-based empirical spectrum in $\mathrm{BN}$. In order to find the reason for the different results from the LP and BN simulations in Group A, we start Group B with experiment BNCNT in which the CNT-based IN spectra of Barahona and Nenes (2009b) are used. In addition, the spectrum is adjusted by applying different values for the maximum freezing ratio of potential ice nuclei $\left(f_{\max }\right)$.

The $N_{\mathrm{i}}$ PDFs in the SGP region given by this set of simulations are shown in Fig. 7. As $f_{\max }$ increases from $5 \%$ to $100 \%$ (panels a to d), the peak of the PDF in the lowtemperature range $\left(<-55^{\circ} \mathrm{C}\right)$ gradually shifts to lower concentrations. For the two simulations with the largest and smallest $f_{\max }$, we calculated the breakdown of ice crystal production and the nucleation frequencies as in the previous section. While the BNCNT run with $f_{\max }=5 \%$ produces similar results to the default BN simulation in Group A, the BNCNT run with $f_{\max }=100 \%$ turns out remarkably similar to the LP simulation (Fig. 8). With a larger $f_{\max }$ (i.e., more IN), not only are more crystals produced by heterogeneous nucleation (Fig. 8, left panel) but also the homogeneous nucleation becomes suppressed (Fig. 8, right panel) and contributes considerably less to the total crystal production (Fig. 8, left panel). Consequently, the total $N_{\mathrm{i}}$ in the SGP region decreases by more than $60 \%$ (not shown). As for the global scale, Fig. 9 illustrates the annually and zonally averaged $N_{\mathrm{i}}$ in the two simulations. In the Northern Hemisphere, where the main sources of dust aerosols are located, a larger $f_{\text {max }}$ leads to considerably less ice crystals between 100 and $200 \mathrm{hPa}$. (In Fig. 9c, differences smaller than the standard deviation of the monthly mean values have been masked out.)

Results from this set of sensitivity experiments indicate that differences in the IN spectrum are probably the main reason for the discrepancies seen earlier between the default LP and BN simulations. Better agreement with the SPARTICUS measurements can be obtained either with an observationbased spectrum or a CNT-based spectrum with a rather low freezing ratio $(5 \%)$. A larger $f_{\max }$ (as, e.g., in the LP05 scheme) causes stronger heterogeneous nucleation and suppressed homogeneous nucleation, which can result in lower $N_{\mathrm{i}}$ in global simulations. 

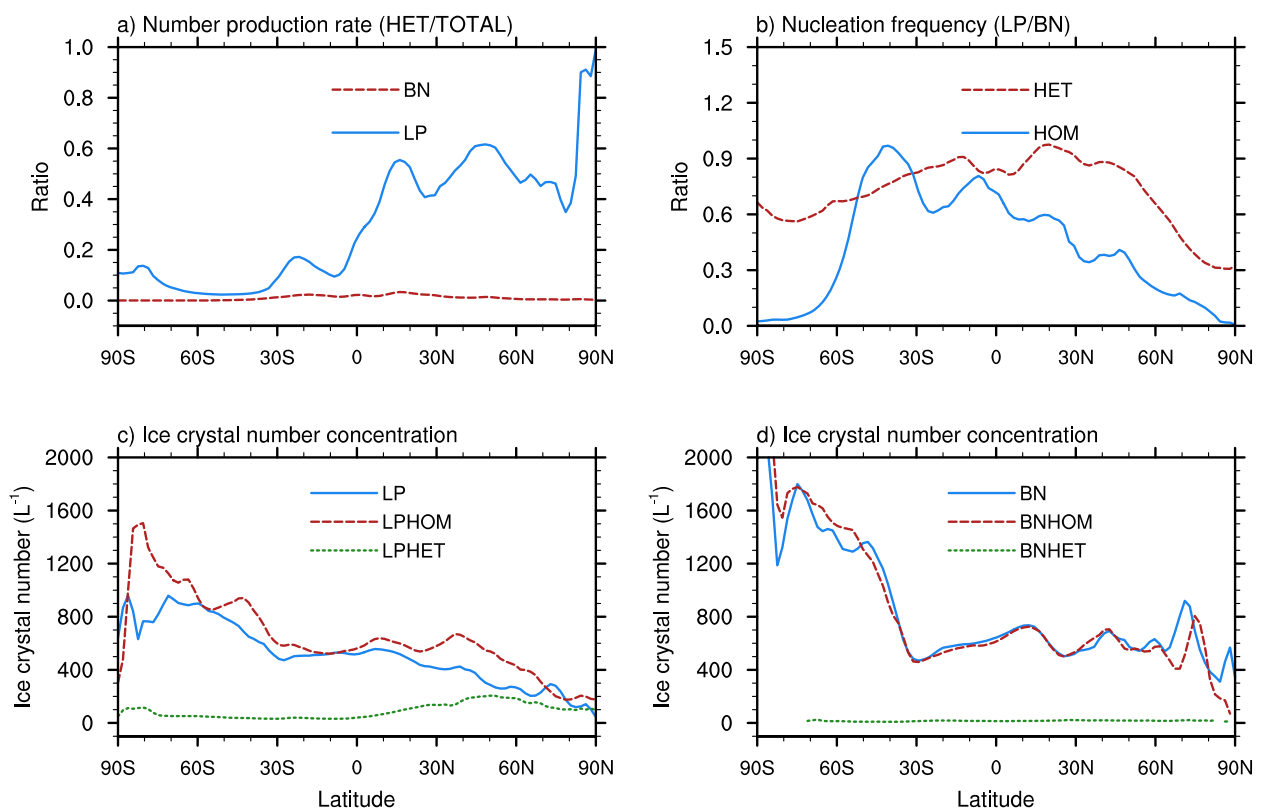

Fig. 5. (a) Contribution of heterogeneous ice nucleation to total crystal number production in the LP05 and BN09 simulations. (b) Differences between the LP05 and BN09 simulations in terms of the occurrence frequency of the two nucleation mechanisms, given as the LP: BN ratio. (c)-(d) In-cirrus $N_{\mathrm{i}}$ (unit: $\mathrm{L}^{-1}$ ) in different simulations of Group A in Table 2. All quantities shown are based on zonal and annual averages on the $200 \mathrm{hPa}$ pressure level.

\subsection{Sensitivity to the water vapor deposition coefficient $\alpha$}

In the BN09 ice nucleation scheme, the water vapor deposition coefficient $\alpha$ is a tunable parameter that directly affects the supersaturation over ice (cf. Eqs. (1) and (4)-(6) in Barahona and Nenes, 2008), which then determines the size distribution of ice crystals. This reflects the competition for available water vapor between crystal formation and crystal growth. Simulations in Group C reveal that an increase of $\alpha$ from the default value 0.1 to 0.5 leads to little change in the results (Fig. 10a), while a decrease in the parameter results in shifts of the $N_{\mathrm{i}}$ PDF at all temperatures shown in Fig. 10. In the SGP region, $\alpha=0.05$ gives the best agreement between simulated and the measured $N_{\mathrm{i}}$, while the value 0.006 , based on laboratory measurements at $-50^{\circ} \mathrm{C}$ from Magee et al. (2006), leads to about $400 \%$ positive biases at this and lower temperatures (not shown). Compared to the default configuration $(\alpha=0.1), N_{\mathrm{i}}$ simulated with $\alpha=0.006$ are about factor of 9 higher at and below $-50^{\circ} \mathrm{C}$, similar to results obtained by Lohmann et al. (2008) with the ECHAM5 model.

On the global scale, decreasing $\alpha$ from 0.1 to 0.05 and 0.006 can lead to more than $50 \%(\alpha=0.05)$ and a factor of $5(\alpha=0.006)$ increases of $N_{\mathrm{i}}$, respectively in the upper troposphere (excluding tropical regions, Fig. 11). Unlike $f_{\max }$, which mainly affects the Northern Hemisphere middle and high latitudes, the impact of $\alpha$ is global, and more symmetric with respect to the equator.

\subsection{Sensitivity to the critical crystal diameter $D_{\text {cs }}$}

The critical diameter $D_{\mathrm{cs}}$ that separates cloud and snow is an artificial parameter in bulk cloud microphysics parameterizations. In the scheme of Morrison and Gettelman (2008), it shows up only in the autoconversion from ice to snow. With a larger $D_{\mathrm{cs}}$, less crystals are converted to the snow class and precipitate, resulting in a larger average size of the ice crystals remaining in the atmosphere. This is indeed seen in the crystal effective diameter at all temperature ranges shown in Fig. 12 (orange-colored triangles). In order to minimize the impact of mix-phase clouds on the analysis, the measurement records and model results that include nonzero cloud droplet number concentrations have been excluded. The $D_{\mathrm{cs}}$ value of $250 \mu \mathrm{m}$ produces a simulation that matches best with the SPARTICUS measurements. The algorithm used for deriving the observed effective diameter is described by Mitchell et al. (2011). $D_{\text {cs }}=325 \mu \mathrm{m}$ and $400 \mu \mathrm{m}$ (the default values in CAM5.0 and CAM5.1, respectively) result in larger effective diameters for ice crystals (Fig. 12c, d) and little change in $N_{\mathrm{i}}$ (not shown). Consequently, the ice water path is larger, and so is the longwave cloud forcing (Table 6).

It is worth noting that the measurements from SPARTICUS may contain snow particles of up to $3000 \mu \mathrm{m}$ due to the characteristics of the instruments. The observation-based effective diameters in Fig. 12 thus may contain positive biases especially at warmer temperatures. Based on this consideration, the overestimated effective diameters in the model with $D_{\text {cs }}=325 \mu \mathrm{m}$ and $400 \mu \mathrm{m}$ suggest that these values for the 

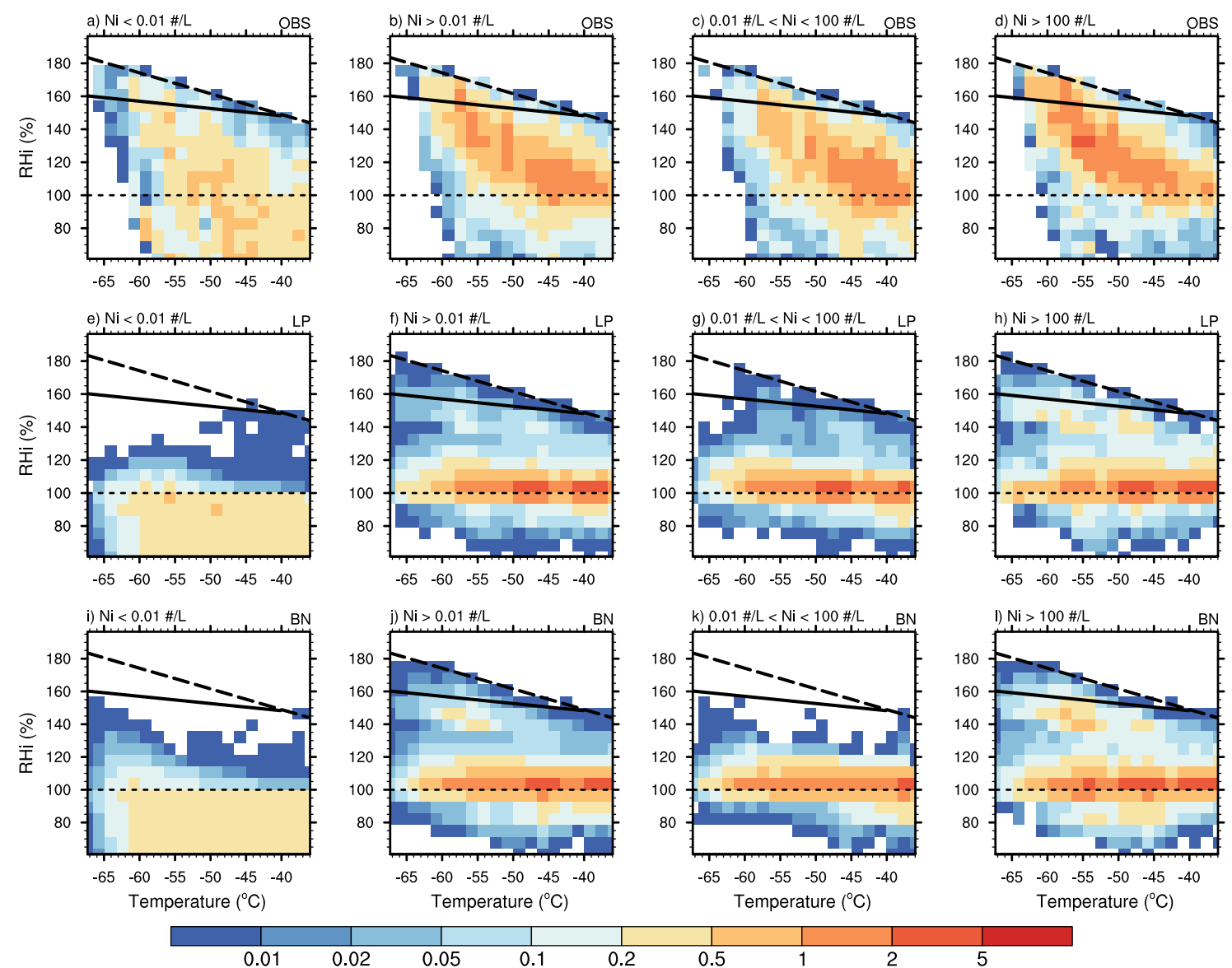

Fig. 6. Observed and simulated joint probability density function (PDF) of relative humidity with respect to ice $\left(\mathrm{RH}_{\mathrm{i}}\right.$, unit: \%) and ambient temperature (unit: ${ }^{\circ} \mathrm{C}$ ) in the upper troposphere (above $500 \mathrm{hPa}$ ), in clear-sky conditions $\left(N_{\mathrm{i}}<0.01 \mathrm{~L}^{-1}\right.$, first column), and inside cirrus clouds $\left(N_{\mathrm{i}}>0.01 \mathrm{~L}^{-1}\right.$, second column). The in-cirrus cases are further divided into two subgroups with different $N_{\mathrm{i}}$ ranges: $0.01 \mathrm{~L}^{-1}<$ $N_{\mathrm{i}}<100 \mathrm{~L}^{-1}$ (third column) and $N_{\mathrm{i}}>100 \mathrm{~L}^{-1}$ (rightmost column). The observed PDF is derived from $1 \mathrm{~Hz}$ measurements in the SGP area obtained during the SPARTICUS campaign. The simulated PDFs are computed from $5 \mathrm{yr}$ of instantaneous 3-hourly model output in the SGP area (cf. Fig. 1) in the months when the measurements were taken. The horizontal dotted line indicates ice saturation $\left(\mathrm{RH}_{\mathrm{i}}=100 \%\right)$. The thick dashed line indicates water saturation. The solid black line indicates the $\mathrm{RH}_{\mathrm{i}}$ threshold for homogeneous freezing of liquid solution droplets with $0.5 \mu \mathrm{m}$ radius calculated according to Koop et al. (2000).

separating diameter are indeed on the large side. Although the top-of-atmosphere radiative balance is achieved in the corresponding model versions, the partition of radiative forcing between cold and warm clouds may be biased.

\subsection{Climate impact}

Results presented above indicate that the simulated ice crystal size and number concentration are sensitive to empirical parameters in cloud microphysics, including ice nucleation parameterization. To assess the climate impact, Table 6 lists key variables that describe the global mean topof-atmosphere (TOA) cloud forcing and hydrological cycle in the sensitivity simulations.

Among the four groups of simulations, the selected metrics are most sensitive to the water vapor deposition coefficient $\alpha$ and the crystal/snow separating diameter $D_{\mathrm{cs}}$. When the deposition coefficient is changed from 0.1 to 0.006 , the more than factor of 5 higher $N_{\mathrm{i}}$ in the upper troposphere (Fig. 11b) results in an LWCF increase of about $15 \mathrm{~W} \mathrm{~m}^{-2}$, a high-cloud fraction increase of about $20 \%$, and an ice water path (IWP) increase of $30 \%$. The surface precipitation rate reduces by about $11 \%$. The simulated LWCF $\left(47.1 \mathrm{~W} \mathrm{~m}^{-2}\right)$ features a $74 \%$ positive bias compared to the observation $\left(27 \mathrm{~W} \mathrm{~m}^{-2}\right)$. With $\alpha=0.05$, the LWCF, high-cloud fraction, and ice water path are also larger than those simulated with the default value, but the changes are moderate.

The critical diameter $D_{\mathrm{cs}}$ also has clear impacts on the simulated climate, especially the TOA net radiation flux. In another recent work (Zhao et al., 2013), $D_{\mathrm{cs}}$ is also identified as one of the most influential parameters for TOA net radiation flux in their CAM5 simulations. This explains why it is often used as the main tuning parameter for radiative balance. 
Table 6. Cloud forcing and hydrological variables in various sensitivity simulations. Shown are globally and annually averaged top-ofatmosphere (TOA) longwave cloud forcing (LWCF), TOA shortwave cloud forcing (SWCF), TOA total cloud forcing (TCF), TOA net radiation flux (Fnet), cloud fraction of high clouds (CLDHGH), surface precipitation (PREC), ice water path (IWP), and liquid water path (LWP).

\begin{tabular}{|c|c|c|c|c|c|c|c|c|c|}
\hline Group & Experiment & $\begin{array}{c}\mathrm{LWCF} \\
\left(\mathrm{Wm}^{-2}\right)\end{array}$ & $\begin{array}{c}\text { SWCF } \\
\left(\mathrm{W} \mathrm{m}^{-2}\right)\end{array}$ & $\begin{array}{c}\mathrm{TCF} \\
\left(\mathrm{W} \mathrm{m}^{-2}\right)\end{array}$ & $\begin{array}{c}\text { Fnet } \\
\left(\mathrm{Wm}^{-2}\right)\end{array}$ & $\begin{array}{c}\text { CLDHGH } \\
(\%)\end{array}$ & $\begin{array}{c}\text { PREC } \\
\left(\mathrm{mmd}^{-1}\right)\end{array}$ & $\begin{array}{c}\text { IWP } \\
\left(\mathrm{g} \mathrm{m}^{-2}\right)\end{array}$ & $\begin{array}{c}\text { LWP } \\
\left(\mathrm{g} \mathrm{m}^{-2}\right)\end{array}$ \\
\hline A & LP & 32.2 & -56.8 & -24.6 & 6.04 & 44.0 & 2.77 & 21.3 & 43.0 \\
\hline \multirow[t]{2}{*}{ B } & BNCNT & 31.7 & -56.5 & -24.8 & 6.04 & 42.3 & 2.77 & 20.9 & 42.8 \\
\hline & BNCNT_F10 & 31.4 & -56.2 & -24.8 & 6.03 & 42.3 & 2.77 & 20.8 & 42.6 \\
\hline \multirow[t]{3}{*}{$\mathrm{C}$} & BN_ $\alpha 0.5$ & 31.9 & -56.6 & -24.7 & 6.13 & 42.7 & 2.77 & 21.1 & 42.8 \\
\hline & BN_ $\alpha 0.05$ & 34.9 & -59.4 & -24.5 & 6.61 & 44.6 & 2.71 & 22.4 & 43.5 \\
\hline & BN_ $\alpha 0.006$ & 47.1 & -72.2 & -25.1 & 7.29 & 52.7 & 2.47 & 32.2 & 45.8 \\
\hline $\mathrm{D}$ & BN_Dcs175 & 28.2 & -57.3 & -29.0 & 1.86 & 38.7 & 2.86 & 10.1 & 43.8 \\
\hline
\end{tabular}
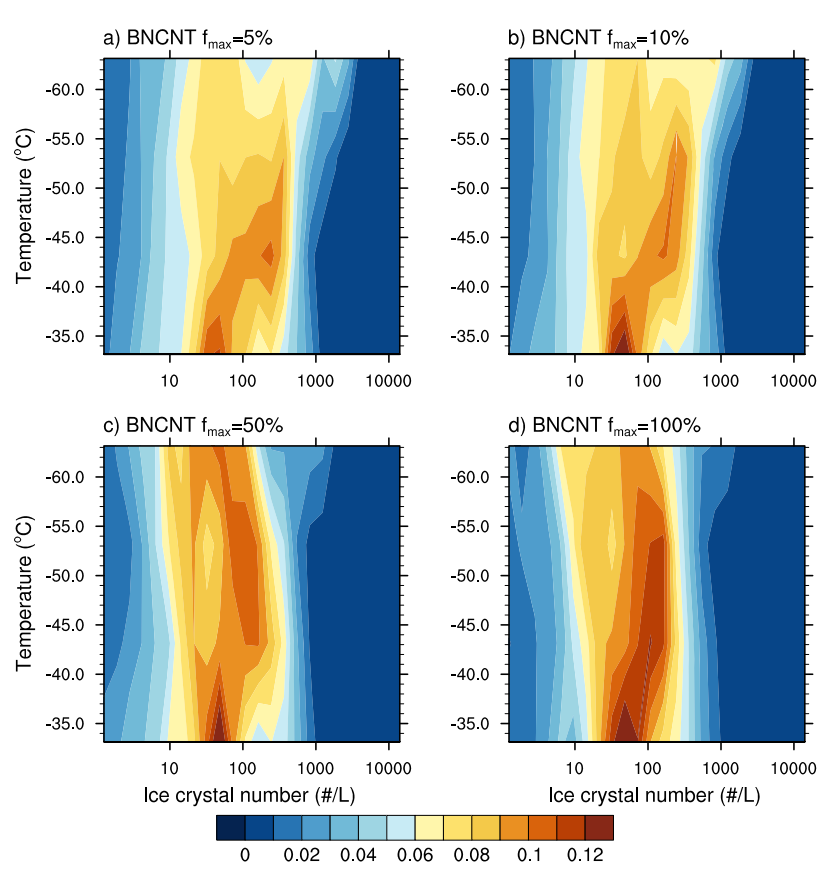

Fig. 7. As in Fig. 3, but for simulations in Group B. The simulations are performed with the BN09 ice nucleation scheme with a classical-theory-based IN spectra and different values for the maximum freezing ratio of potential ice nuclei $\left(f_{\max }\right)$. Further details can be found in Table 3 (Group B) and Sect. 5.2.
When the value is changed from $400 \mu \mathrm{m}$ to $250 \mu \mathrm{m}$, which matches the observation, the simulated IWP decreases by $37 \%$ and the longwave cloud forcing decreases by $1 \mathrm{Wm}^{-2}$. $N_{\mathrm{i}}$ is only slightly higher because of a weaker sedimentation sink (not shown). Because the IWP is smaller, the Bergeron-Findeisen process is less sufficient and the liquid water path (LWP) becomes larger. The shortwave cloud forcing increases by $1.9 \mathrm{~W} \mathrm{~m}^{-2}$ primarily due to the larger LWP.

$f_{\text {max }}$ has a relatively small impact on the global mean metrics because it is directly related to the heterogeneous nucleation. Thus, the influence is limited in terms of spatial coverage.

\section{Discussion and conclusions}

In this work we use aircraft measurements of ice crystal size distribution and relative humidity collected during the SPARTICUS campaign to evaluate the simulated characteristics of synoptic cirrus clouds in the Northern Hemisphere midlatitudes. A series of simulations are performed to compare the LP05 and BN09 ice nucleation parameterizations in CAM5, focusing on the sensitivity of model results to three empirical parameters: the maximum freezing fraction of dust aerosols $\left(f_{\max }\right)$, the deposition coefficient of water vapor on ice $(\alpha)$, and the critical diameter $D_{\mathrm{cs}}$ that distinguishes cloud ice and snow as two classes of ice-phase hydrometeors. These parameters are commonly used in current climate models, but their values have not yet been well constrained by direct observations or laboratory experiments, or have been repeated tuned in global models for the purpose of, e.g., achieving balance in the energy budget at the top of atmosphere. In this 

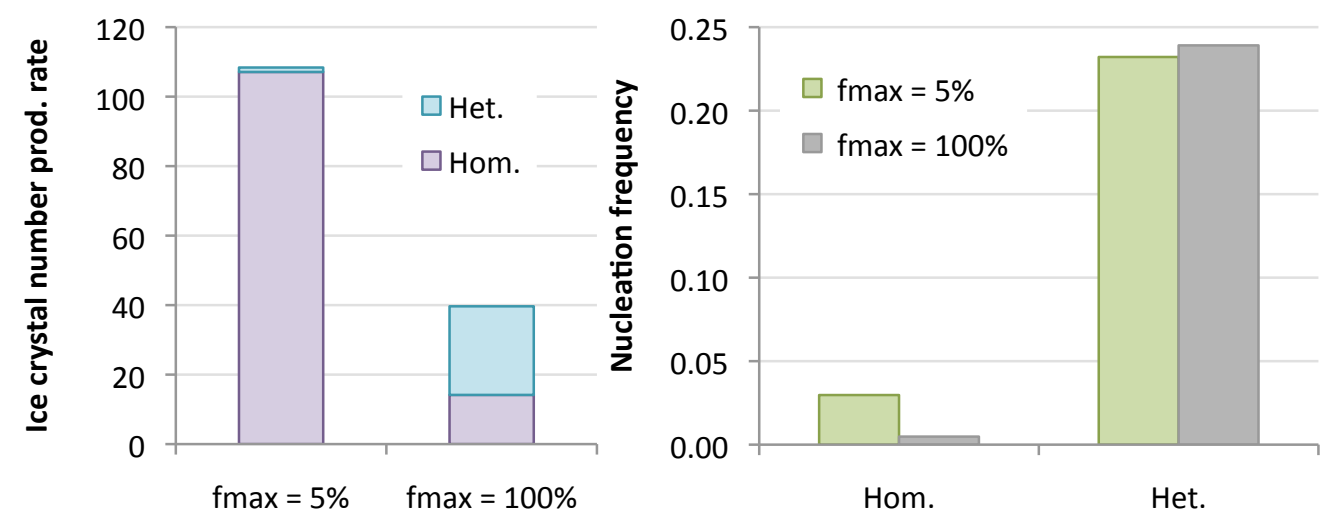

Fig. 8. As in Fig. 4, but comparing two simulations performed with the BN09 ice nucleation scheme using a classical-theory-based IN spectra and different values for the maximum freezing ratio of potential ice nuclei $\left(f_{\max }\right)$. Further details can be found in Table 3 (Group B) and Sect. 5.2.
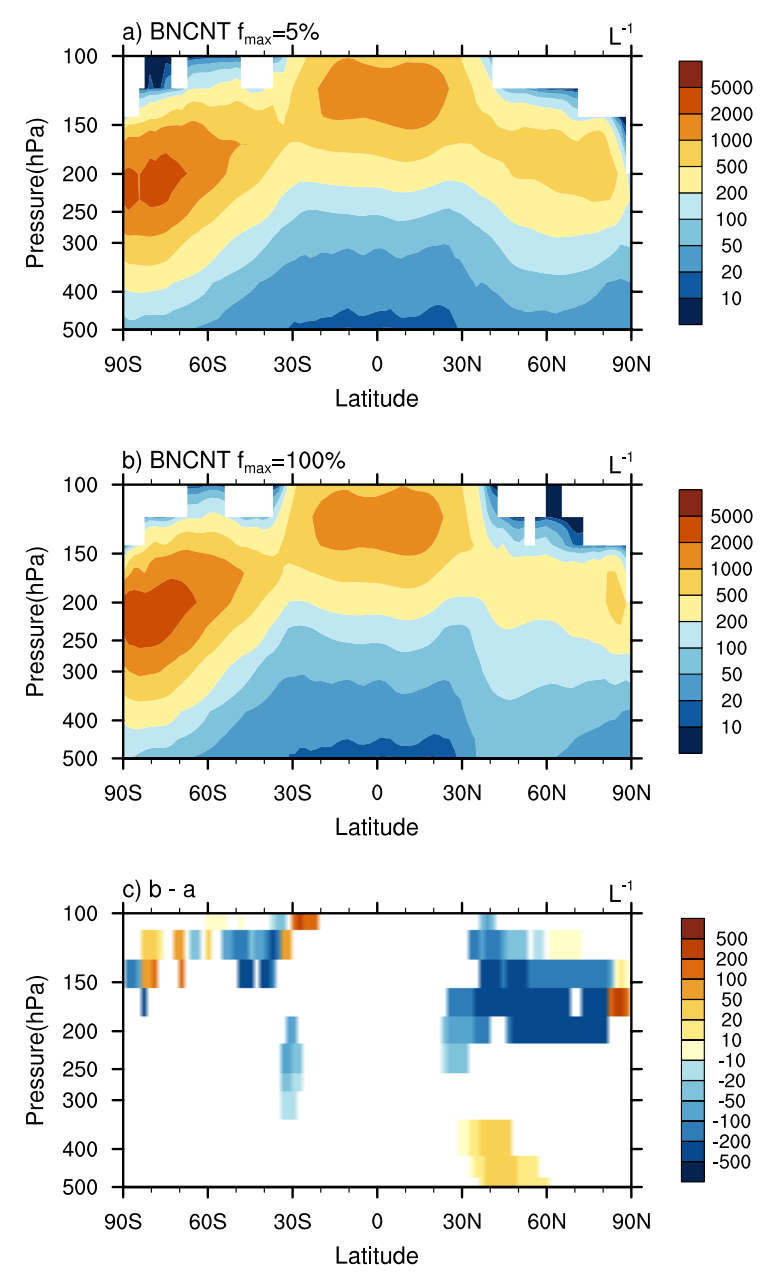

Fig. 9. Annually and zonally averaged in-cloud $N_{\mathrm{i}}\left(\mathrm{L}^{-1}\right)$ simulated with the BN09 ice nucleation scheme using a classical-theory-based IN spectra and different values for the maximum freezing ratio of potential ice nuclei $\left(f_{\max }\right)$. Further details can be found in Table 3 (Group B) and Sect. 5.2. paper we attempt to constrain these parameters by comparing the observed and simulated $N_{\mathrm{i}}$ and crystal size in synoptic cirrus clouds, and we analyze the parameter-induced sensitivity by looking into the relative role of different ice nucleation mechanisms (heterogeneous and homogeneous nucleation). Although the investigation is focused on one model (CAM5) in this work, we believe the analysis of the observational data and the results from our sensitivity experiments provide useful information to readers beyond the CAM5 user community.

The aircraft measurements from SPARTICUS reveal a strong dependency of $N_{\mathrm{i}}$ on ambient temperature. As temperature decreases from $-35^{\circ} \mathrm{C}$ (about $240 \mathrm{~K}$ ) to $-62^{\circ} \mathrm{C}$ (about $210 \mathrm{~K}$ ), the peak in the $N_{\mathrm{i}}$ PDF shifts from $10-20 \mathrm{~L}^{-1}$ to $200-1000 \mathrm{~L}^{-1}$. Consistently, the observed $N_{\mathrm{i}}$ shows a factor of 6-7 increase. These features appear different from the observational data used in Fig. 5 of Liu et al. (2012b), where measurements obtained by Krämer et al. (2009) from different regions (tropics, midlatitudes, the Arctic) and different types of cirrus (anvil, synoptic) were compiled together for model evaluation. The differences suggest that zooming into a specific (Northern Hemisphere midlatitude) region and a particular type of cirrus clouds can provide more detailed information to support quantitative evaluation of processbased models and parameterizations.

Potentially, the focus on SPARTICUS may lead to overfitting the model behavior to a single campaign. In Appendix A we showed that the MACPEX data, obtained with the same 2D-S probe, indicate a similar relationship between $N_{\mathrm{i}}$ and the ambient temperature, while the midlatitude flights contained in the dataset of Krämer et al. (2009) have different features. It is worth noting that the Krämer et al. (2009) dataset contains only four flights from the midlatitude regions, while the SPARTICUS campaign collected about $200 \mathrm{~h}$ of data in the time span of 6 months, providing the longest continuous dataset available so far for cirrus clouds. In addition, the new 2D-S probe has been shown to be less 


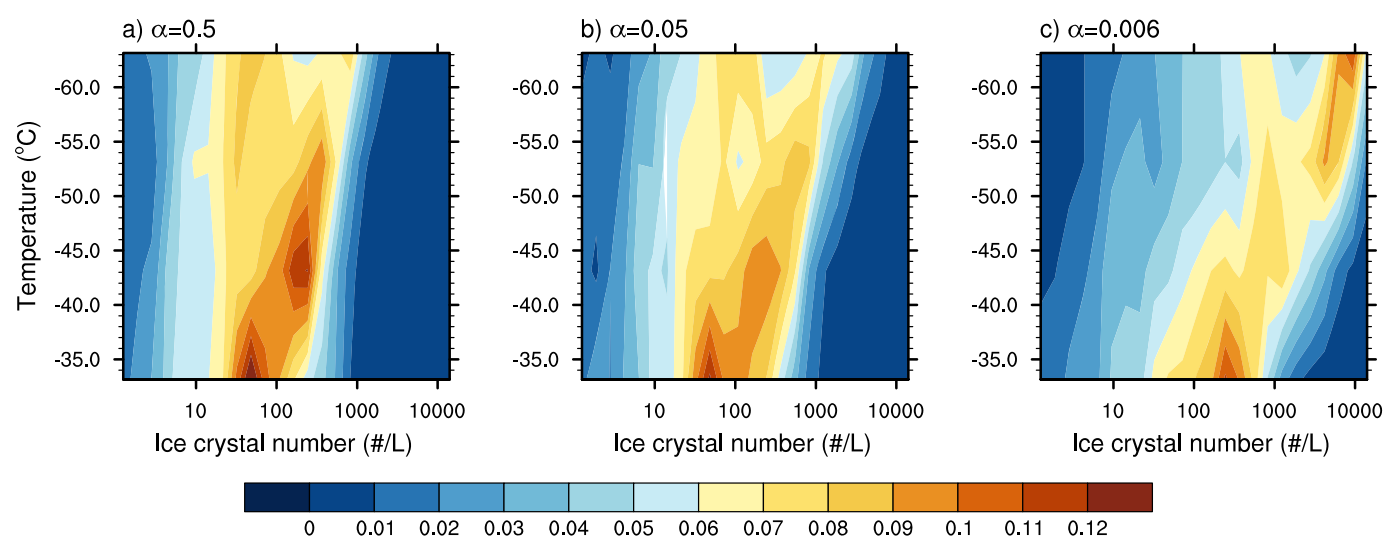

Fig. 10. As in Fig. 3, but for simulations in Group C. Further details can be found in Table 3 and Sect. 5.3.
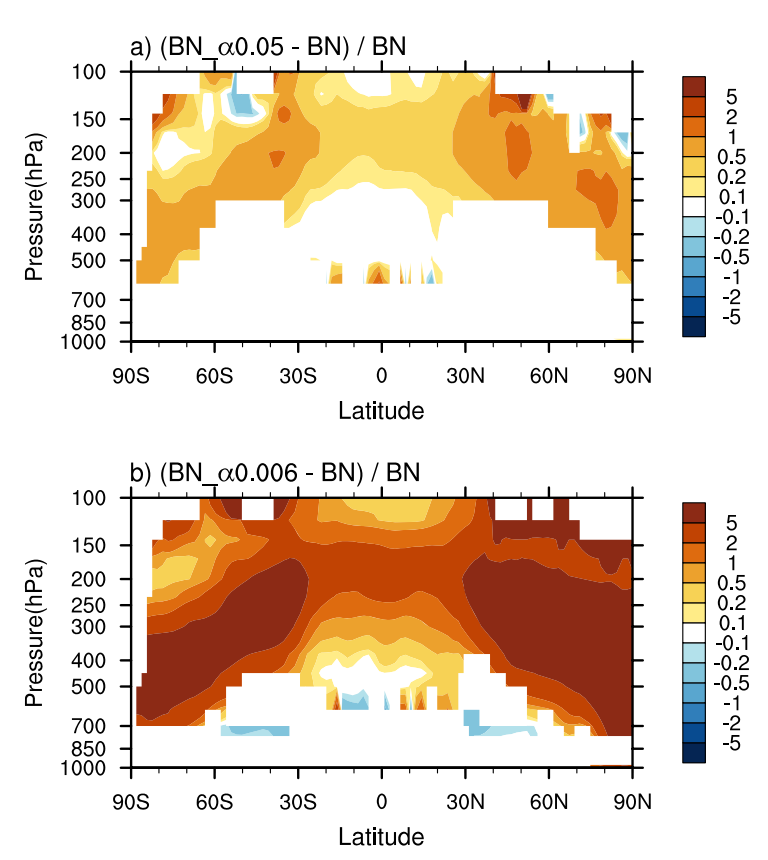

Fig. 11. Relative differences in the zonally and annually averaged in-cloud $N_{\mathrm{i}}$ between simulations that use different water vapor deposition coefficient $(\alpha)$ in the BN09 ice nucleation scheme.

susceptible to the potential measurement biases in $N_{\mathrm{i}}$ related to the shattering of large crystals (Lawson et al., 2006; Lawson, 2011). We acknowledge that it is not yet clear whether the conclusions drawn from the $\mathrm{NH}$ midlatitude continental observations presented in the paper also hold, e.g., over the $\mathrm{NH}$ oceans and in the Southern Hemisphere. This highlights the value of - and the need for - more long-term observations like SPARTICUS in helping to improve our understanding of ice clouds as well as our ability to simulate them in climate models.

As for the tropical regions, Liu et al. (2012b) showed that when the ambient temperature is lower than $205 \mathrm{~K}$, the $N_{\mathrm{i}}$ values simulated with CAM5 (with either the LP05 or the
BN09 scheme) are more than an order of magnitude higher than the observations in Krämer et al. (2009). A plausible explanation is that glassy organic aerosols, which can act as efficient ice nuclei and thus inhibit homogeneous nucleation, are not considered in the current model (Jensen et al., 2010; Murray et al., 2010). This issue, related to missing components in the model, is considered as out of the scope of the present paper.

In this study we show that the clear dependency of $N_{\mathrm{i}}$ on temperature in the SGP area can be reproduced by the CAM5 model when using the BN09 ice nucleation parameterization but not with the LP05 scheme due to differences in the relative contribution of different nucleation mechanisms. Sensitivity simulations in Groups A and B further identify the IN spectrum as the key reason. When a classical-theorybased IN spectrum is used in combination with a high maximum freezing ratio $f_{\max }$ of the potential IN population (as in the LP05 scheme and in the BNCNT_F100 simulation), the heterogeneous nucleation plays an important role in ice crystal production and strongly suppresses the homogeneous nucleation. In contrast, when $f_{\max }$ is set to $5 \%$ or when an observation-based empirical IN spectrum is used, homogeneous nucleation plays a dominant role in ice crystal production, and the increase of $N_{\mathrm{i}}$ at colder temperature can be better reproduced. At the global scale, the impact can be clearly seen in the Northern Hemisphere, where the main sources of dust aerosol are located. These results suggest that using high $f_{\max }$ for classical-theory-based IN spectrum may lead to overestimation of the climate impact of dust aerosols on cirrus clouds.

Simulations in Group C evaluate different values of the deposition coefficient $\alpha$ of water vapor on ice used in the homogeneous nucleation of BN09. Within the tested range (0.5-0.006), a smaller $\alpha$ leads to higher $N_{\mathrm{i}}$ on the global scale, larger ice water path, and stronger longwave and shortwave cloud forcing. The value 0.05 gives the best agreement between the measured and simulated $N_{\mathrm{i}}$ in the SGP area, while the value 0.006 (based on laboratory experiments at 

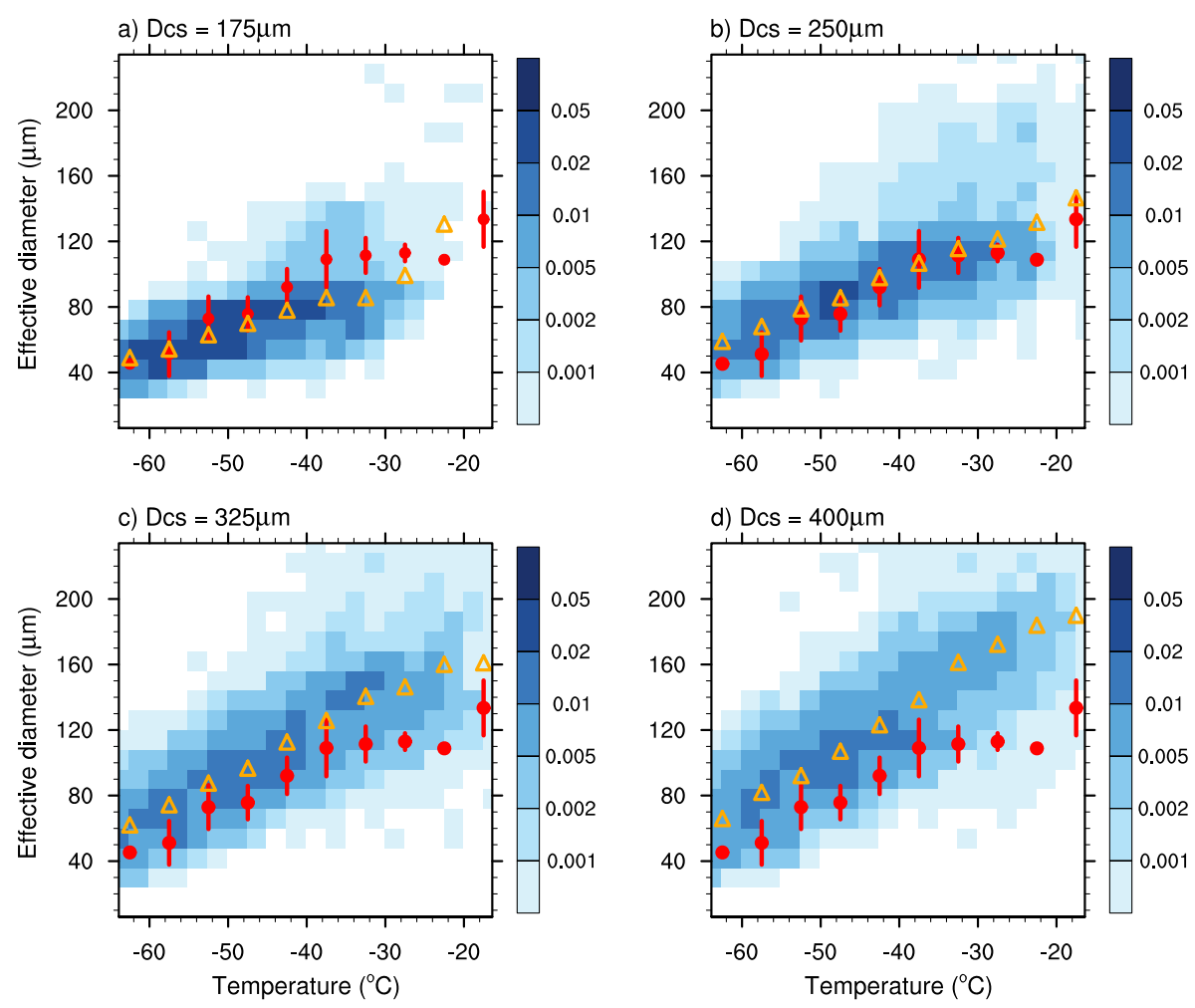

Fig. 12. Color shading shows the bivariate PDF of temperature and the effective diameter of ice crystals simulated with CAM5 using different values of the parameter $D_{\mathrm{cs}}$. Triangles indicate the simulated mean effective diameter at different temperatures. The red dots and whiskers indicate the mean and standard deviation derived from the SPARTICUS measurements.

$-50^{\circ} \mathrm{C}$ ) leads to overly high $N_{\mathrm{i}}$ at all temperature ranges investigated in this study, and too strong cloud radiative forcing. We therefore recommend a value between 0.05 and 0.1 for the CAM5 model. Again, we point out that this recommendation is based on measurements from the SPARTICUS campaign. Whether this range is also the best for other midlatitude regions remains to be seen when more observations become available.

The critical crystal diameter $D_{\mathrm{cs}}$ that distinguishes cloud ice and snow as two different classes of solid-phase condensates in the Morrison and Gettelman (2008) cloud microphysics parameterization has been used as one of the main tuning parameters in recent model versions to achieve the top-of-atmosphere radiative balance in CAM5. While our comparison indicates $D_{\mathrm{cS}}=250 \mu \mathrm{m}$ to provide the best agreement with the SPARTICUS campaign, the default values used in CAM5.0 $(325 \mu \mathrm{m})$ and CAM5.1 $(400 \mu \mathrm{m})$ result in positive biases in the ice crystal effective diameter. This suggest that in the model, the global mean radiative balance may have been achieved at the expense of biases in the microphysical properties of ice crystals, and possibly also in the relative contribution of the radiative forcing from cirrus clouds.

In the future, it will be useful to extend our analyses to more geographical domains and other cold cloud types when new measurements become available. Assimilation techniques such as nudging can provide model capabilities that further facilitate comparison with observations. Moreover, there are many other empirical parameters in the model that are not yet well constrained. In our BN simulation, although $N_{\mathrm{i}}$ at low temperatures are better simulated than with the LP05 scheme, they are still significantly underestimated in comparison to the SPARTICUS measurements. Our recent work has revealed that the subgrid updraft velocity used by the ice nucleation schemes in CAM5 features negative biases in comparison with observations from multiple campaigns, partly due to the artificial upper bound of $0.2 \mathrm{~m} \mathrm{~s}^{-1}$ used in the model, which leads to a factor of $1.5-2$ difference in the average updraft velocity. This could be a reason for the underestimated $N_{\mathrm{i}}$ in the current model because lower updraft velocity may affect the competition between homogeneous and heterogeneous ice nucleation, and thus lead to less frequent homogeneous nucleation (c.f. DeMott et al., 1997; Jensen et al., 1994; Kärcher and Lohmann, 2003; Gettelman et al., 2012). The work on updraft velocity will be reported in a separate paper. 


\section{Appendix A}

Relationship between ambient temperature and $N_{\mathrm{i}}$ in other observation campaigns

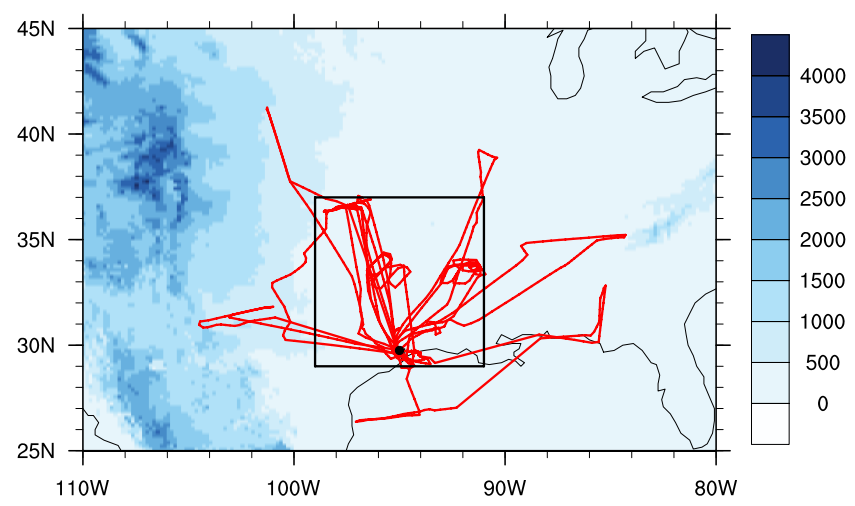

Fig. A1. Aircraft trajectories during the MACPEX field campaign. Color shading shows the surface elevation (unit: $\mathrm{m}$ ). The black dot at $29.75^{\circ} \mathrm{N}, 95.4^{\circ} \mathrm{W}$ shows the location of Houston, TX. The square indicates the area within which $N_{\mathrm{i}}$ are used for model evaluation shown in Fig. A2.

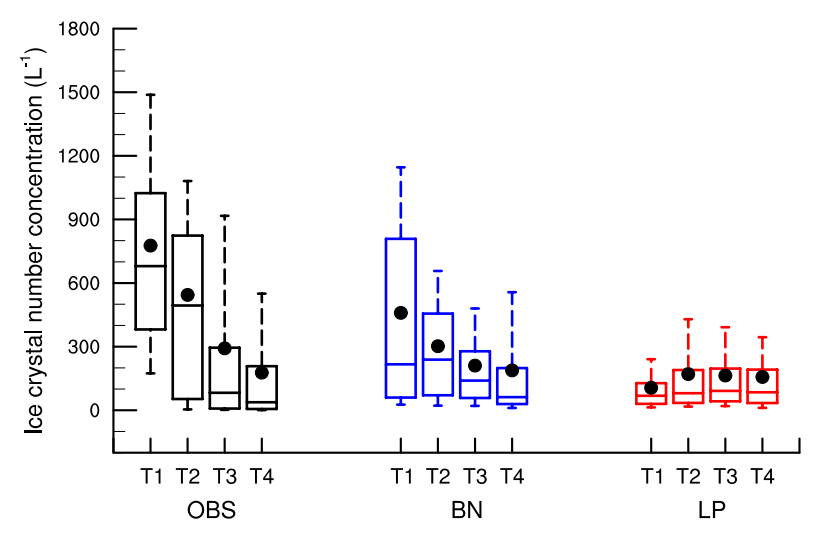

Fig. A2. As in Fig. 2, but showing observations (OBS) from the MACPEX campaign, and model simulations (BN and LP) over the Houston area (i.e., the black square in Fig. A1).

In Sect. 5 we showed that the SPARTICUS observations reveal a marked increase of the $N_{\mathrm{i}}$ with decreasing temperature (Fig. 2a). The CAM5 model with the BN09 ice nucleation parameterization can reproduce a qualitatively similar although weaker relationship (Fig. 2b), while the LP05 scheme gives rather constant $N_{\mathrm{i}}$ values across the different temperature ranges (Fig. 2c). We carried out a similar evaluation using data from the NASA Mid-latitude Airborne Cirrus Properties Experiment (MACPEX, Fig. A1) during which $6 \mathrm{~h}$ of $N_{\mathrm{i}}$ data were collected between 3 and 26 April near the Houston area $\left(29.75^{\circ} \mathrm{N}, 95.4^{\circ} \mathrm{W}\right)$ using the $2 \mathrm{D}$-S probe. The MACPEX measurements show qualitatively the same feature as SPARTICUS (Fig. A2).

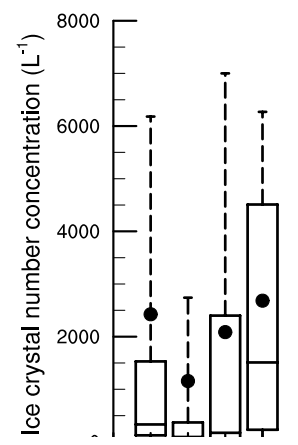

Fig. A3. As the left panel in Fig. 2 but showing measurements obtained with the Forward Scattering Spectrometer Probe (FSSP) during the CIRRUS 2004-2006 flights over Hohn $\left(9.5^{\circ} \mathrm{E}, 54^{\circ} \mathrm{N}\right)$, Germany (Krämer et al., 2009).

In contrast, midlatitude measurements in the dataset of Krämer et al. (2009) from the four CIRRUS 2004-2006 flights over Hohn, Germany $\left(9.5^{\circ} \mathrm{E}, 54^{\circ} \mathrm{N}\right)$, indicate a different $T-N_{\mathrm{i}}$ relationship. The observed $N_{\mathrm{i}}$ (Fig. A3) is rather high in the $235 \mathrm{~K}-245 \mathrm{~K}$ temperature range (which is mostly above the temperature threshold of $235 \mathrm{~K}-236 \mathrm{~K}$ required by homogeneous ice nucleation). It should be noted that the CIRRUS flights used the Forward Scattering Spectrometer Probe (FSSP), which may have the problem of overestimating $N_{\mathrm{i}}$ when clouds contain a significant number of relatively large (diameter $>50 \mu \mathrm{m}$ ) particles, typically appearing at warmer temperatures (see, e.g., Sect. 2.2 in Krämer et al., 2009). Because of the potential issues with crystal shattering, we did not use the Krämer et al. (2009) data for model evaluation in this study.

Acknowledgements. We thank Paul Lawson (SPEC Inc.) for his help with the ice crystal number concentration measured by the 2D-S probe and Glenn S. Diskin (NASA Langley Research Center) for the DLH water vapor measurements. We are also grateful to Xiangjun Shi (IAP/CAS), Eric Jensen (NASA Ames), Donifan Barahona (NASA GSFC), Hugh Morrison (NCAR), and Phil Rasch for helpful discussions. Comments and suggestions from Hui Wan provided through the PNNL internal review are highly appreciated. We also thank the two anonymous referees for their helpful reviews. Kai Zhang and Xiaohong Liu acknowledge support from the NASA Modeling, Analysis and Prediction (MAP) Program. Xiaohong Liu and Minghuai Wang acknowledge support from the DOE Atmospheric System Research (ASR) Program. Jennifer M. Comstock was supported by the DOE Atmospheric Radiation Measurement (ARM) Program. The Pacific Northwest National Laboratory is operated for DOE by Battelle Memorial Institute under contract DE-AC06-76RLO 1830.

Edited by: J. Quaas 


\section{References}

Barahona, D. and Nenes, A.: Parameterization of cirrus cloud formation in large-scale models: homogeneous nucleation, J. Geophys. Res., 113, D11211, doi:10.1029/2007JD009355, 2008.

Barahona, D. and Nenes, A.: Parameterizing the competition between homogeneous and heterogeneous freezing in cirrus cloud formation - monodisperse ice nuclei, Atmos. Chem. Phys., 9, 369-381, doi:10.5194/acp-9-369-2009, 2009a.

Barahona, D. and Nenes, A.: Parameterizing the competition between homogeneous and heterogeneous freezing in ice cloud formation - polydisperse ice nuclei, Atmos. Chem. Phys., 9, 59335948, doi:10.5194/acp-9-5933-2009, 2009b.

Bretherton, C. S. and Park, S.: A new moist turbulence parameterization in the Community Atmosphere Model, J. Climate, 22, 3422-3448, doi:10.1175/2008JCLI2556.1, 2009.

Chen, J.-P., Hazra, A., and Levin, Z.: Parameterizing ice nucleation rates using contact angle and activation energy derived from laboratory data, Atmos. Chem. Phys., 8, 7431-7449, doi:10.5194/acp-8-7431-2008, 2008.

Comstock, J. M., Ackerman, T., and Turner, D.: Evidence of high ice supersaturation in cirrus clouds using ARM Raman lidar measurements, Geophys. Res. Lett., 31, L11106, doi:10.1029/2004GL019705, 2004.

Comstock, J. M., Lin, R.-F., Starr, D., and Yang, P.: Understanding ice supersaturation, particle growth, and number concentration in cirrus clouds, J. Geophys. Res., 113, D23211, doi:10.1029/2008JD010332, 2008.

Cziczo, D. J., Murphy, D. M., Hudson, P. K., and Thomson, D. S.: Single particle measurements of the chemical composition of cirrus ice residue during CRYSTAL-FACE, J. Geophys. Res.Atmos., 109, 4201, doi:10.1029/2003JD004032, 2004.

DeMott, P., Meyers, M., and Cotton, W.: Parameterization and impact of ice initiation processes relevant to numerical model simulations of cirrus clouds, J. Atmos. Sci., 51, 7790, doi:10.1175/1520-0469(1994)051<0077:PAIOII>2.0.CO;2, 1994.

DeMott, P., Rogers, D., and Kreidenweis, S.: The susceptibility of ice formation in upper tropospheric clouds to insoluble aerosol components, J. Geophys. Res., 102, 19575-19584, doi:10.1029/97JD01138, 1997.

DeMott, P. J., Rogers, D. C., Kreidenweis, S. M., Chen, Y., Twohy, C. H., Baumgardner, D., Heymsfield, A. J., and Chan, K. R.: The role of heterogeneous freezing nucleation in upper tropospheric clouds: inferences from SUCCESS, Geophys. Res. Lett., 25, 1387-1390, doi:10.1029/97GL03779, 1998.

DeMott, P. J., Cziczo, D. J., Prenni, A. J., Murphy, D. M., Kreidenweis, S. M., Thomson, D. S., Borys, R., and Rogers, D. C.: Measurements of the concentration and composition of nuclei for cirrus formation, P. Natl. Acad. Sci. USA, 100, 14655-14660, doi:10.1073/pnas.2532677100, 2003.

Deng, M. and Mace, G. G.: Cirrus microphysical properties and air motion statistics using cloud radar Doppler moments. Part I: Algorithm description, J. Appl. Meteorol. Climatol., 45, 1690, doi:10.1175/JAM2433.1, 2006.

Deng, M. and Mace, G. G.: Cirrus microphysical properties and air motion statistics using cloud radar Doppler moments. Part II: Climatology, J. Appl. Meteorol. Climatol., 47, 3221, doi:10.1175/2008JAMC1949.1, 2008.
Detwiler, A.: Comments on "Homogeneous nucleation rate for highly supercooled cirrus cloud droplets", J. Atmos. Sci., 46, 2344-2345, doi:10.1175/15200469(1989)046<2344:CONRFH>2.0.CO;2, 1989.

Diskin, G. S., Podolske, J. R., Sachse, G. W., and Slate, T. A.: Openpath airborne tunable 15 diode laser hygrometer, in: Diode Lasers and Applications in Atmospheric Sensing, edited by: Fried, A., vol. 4187, SPIE Proc., 196-410, 2002.

Earle, M. E., Kuhn, T., Khalizov, A. F., and Sloan, J. J.: Volume nucleation rates for homogeneous freezing in supercooled water microdroplets: results from a combined experimental and modelling approach, Atmos. Chem. Phys., 10, 7945-7961, doi:10.5194/acp-10-7945-2010, 2010.

Ferrier, B.: A double-moment multiple-phase four-class bulk ice scheme: Part I: Description, J. Atmos. Sci., 51, 249-280, 1994.

Field, P. R., Wood, R., Brown, P. R. A., Kaye, P. H., Hirst, E., and Greeaway, R.: Ice particle interarrival times measured with a fast FSSP, J. Atmos. Ocean. Technol., 20, 249-261, doi:10.1175/1520-0426(2003)020<0249:IPITMW>2.0.CO;2, 2003.

Field, P., Heymsfield, A., and Bansemer, A.: Shattering and particle interarrival times measured by optical array probes in ice clouds, J. Atmos. Ocean. Technol., 23, 1357-1371, doi:10.1175/JTECH1922.1, 2006a.

Field, P. R., Möhler, O., Connolly, P., Krämer, M., Cotton, R., Heymsfield, A. J., Saathoff, H., and Schnaiter, M.: Some ice nucleation characteristics of Asian and Saharan desert dust, Atmos. Chem. Phys., 6, 2991-3006, doi:10.5194/acp-6-2991-2006, 2006 b.

Gardiner, B. A. and Hallett, J.: Degradation of In-Cloud Forward Scattering Spectrometer Probe Measurements in the Presence of Ice Particles, Journal of Atmospheric and Oceanic Technology, 2, 171-180, doi:10.1175/15200426(1985)002<0171:DOICFS>2.0.CO;2, 1985.

Gettelman, A., Morrison, H., and Ghan, S. J.: A new twomoment bulk stratiform cloud microphysics scheme in the Community Atmosphere Model, version 3 (CAM3). Part II: Single-column and global results, J. Climate, 21, 3660-3679, doi:10.1175/2008JCLI2116.1, 2008.

Gettelman, A., Liu, X., Ghan, S. J., Morrison, H., Park, S., Conley, A. J., Klein, S. A., Boyle, J., Mitchell, D. L., and Li, J.-F. L.: Global simulations of ice nucleation and ice supersaturation with an improved cloud scheme in the Community Atmosphere Model, J. Geophys. Res., 115, D18216, doi:10.1029/2009JD013797, 2010.

Gettelman, A., Liu, X., Barahona, D., Lohmann, U., and Chen, C.: Climate impacts of ice nucleation, J. Geophys. Res., 117, D20201, doi:10.1029/2012JD017950, 2012.

Gierens, K.: On the transition between heterogeneous and homogeneous freezing, Atmos. Chem. Phys., 3, 437-446, doi:10.5194/acp-3-437-2003, 2003.

Goff, J. A. and Gratch, S.: Low-pressure properties of water from -160 to 212 F, in: Transactions of the American Society of Heating and Ventilating Engineers, 52nd Annual Meeting of the American Society of Heating and Ventilating Engineers, 95-122, 1946.

Haag, W., Kärcher, B., Ström, J., Minikin, A., Lohmann, U., Ovarlez, J., and Stohl, A.: Freezing thresholds and cirrus cloud formation mechanisms inferred from in situ measurements of relative 
humidity, Atmos. Chem. Phys., 3, 1791-1806, doi:10.5194/acp3-1791-2003, 2003.

Heymsfield, A. J.: Precipitation development in stratiform ice clouds: a microphysical and dynamical study, J. Atmos. Sci., 34, 367-381, doi:10.1175/15200469(1977)034<0367:PDISIC > 2.0.CO;2, 1977.

Hoose, C., Kristjánsson, J. E., Chen, J. P., and Hazra, A.: A classical-theory-based parameterization of heterogeneous ice nucleation by mineral dust, soot, and biological particles in a global climate model, J. Atmos. Sci., 67, 2483-2503, doi:10.1175/2010JAS3425.1, 2010.

Iacono, M., Delamere, J., Mlawer, E., Shephard, M., Clough, S., and Collins, W.: Radiative forcing by long-lived greenhouse gases: calculations with the AER radiative transfer models, J. Geophys. Res., 113, D13103, doi:10.1029/2008JD009944, 2008.

Jensen, E. J. and Toon, O. B.: Ice nucleation in the upper troposphere: sensitivity to aerosol number density, temperature, and cooling rate, Geophys. Res. Lett., 21, 2019-2022, doi:10.1029/94GL01287, 1994.

Jensen, E. J., Toon, O. B., Westphal, D. L., Kinne, S., and Heymsfield, A. J.: Microphysical modeling of cirrus: 2. Sensitivity studies, J. Geophys. Res., 99, 10443-10454, doi:10.1029/94JD00226, 1994

Jensen, E. J., Toon, O. B., Tabazadeh, A., Sachse, G. W., Anderson, B. E., Chan, K. R., Twohy, C. W., Gandrud, B., Aulenbach, S. M., Heymsfield, A., Hallett, J., and Gary, B.: Ice nucleation processes in upper tropospheric wave-clouds observed during SUCCESS, Geophys. Res. Lett., 25, 1363-1366, doi:10.1029/98GL00299, 1998.

Jensen, E. J., Lawson, P., Baker, B., Pilson, B., Mo, Q., Heymsfield, A. J., Bansemer, A., Bui, T. P., McGill, M., Hlavka, D., Heymsfield, G., Platnick, S., Arnold, G. T., and Tanelli, S.: On the importance of small ice crystals in tropical anvil cirrus, Atmos. Chem. Phys., 9, 5519-5537, doi:10.5194/acp-9-5519-2009, 2009.

Jensen, E. J., Pfister, L., Bui, T.-P., Lawson, P., and Baumgardner, D.: Ice nucleation and cloud microphysical properties in tropical tropopause layer cirrus, Atmos. Chem. Phys., 10, 13691384, doi:10.5194/acp-10-1369-2010, 2010.

Kärcher, B. and Burkhardt, U.: A cirrus cloud scheme for general circulation models, Q. J. Roy. Meteorol. Soc., 134, 1439-1461, doi:10.1002/qj.301, 2008

Kärcher, B. and Lohmann, U.: A parameterization of cirrus cloud formation: homogeneous freezing of supercooled aerosols, J. Geophys. Res., 107, AAC 4-1-AAC 4-10, doi:10.1029/2001JD000470, 2002.

Kärcher, B. and Lohmann, U.: A parameterization of cirrus cloud formation: heterogeneous freezing, J. Geophys. Res.-Atmos., 108, 4402, doi:10.1029/2002JD003220, 2003.

Kärcher, B., Möhler, O., DeMott, P. J., Pechtl, S., and Yu, F.: Insights into the role of soot aerosols in cirrus cloud formation, Atmos. Chem. Phys., 7, 4203-4227, doi:10.5194/acp-7-4203-2007, 2007.

Kärcher, B. and Spichtinger, B.: Cloud-controlling factors of cirrus, in: Clouds in the Perturbed Climate System: Their Relationship to Energy Balance, Atmospheric Dynamics, and Precipitation, edited by: Heintzenberg, J. and Charlson, R. J., Strüngmann Forum Report, 3536, 235-267, The MIT Press, Cambridge, MA, USA, 2009.
Khvorostyanov, V. I. and Sassen, K.: Cirrus cloud simulation using explicit microphysics and radiation. Part I: Model description., J. Atmos. Sci., 55, 1808-1821, doi:10.1175/15200469(1998)055<1808:CCSUEM>2.0.CO;2, 1998.

Knollenberg, R. G.: The optical array: an alternative to scattering or extinction for airborne particle size determination, J. Appl. Meteorol., 9, 86-103, 1970.

Koop, T., Luo, B., Tsias, A., and Peter, T.: Water activity as the determinant for homogeneous ice nucleation in aqueous solutions, Nature, 406, 611-614, doi:10.1038/35020537, 2000.

Kooperman, G. J., Pritchard, M. S., Ghan, S. J., Wang, M., Somerville, R. C. J., and Russell, L. M.: Constraining the influence of natural variability to improve estimates of global aerosol indirect effects in a nudged version of the Community Atmosphere Model 5, J. Geophys. Res. Atmos., 117, 2156-2202, doi:10.1029/2012JD018588, 2012.

Krämer, M., Schiller, C., Afchine, A., Bauer, R., Gensch, I., Mangold, A., Schlicht, S., Spelten, N., Sitnikov, N., Borrmann, S., de Reus, M., and Spichtinger, P.: Ice supersaturations and cirrus cloud crystal numbers, Atmos. Chem. Phys., 9, 3505-3522, doi:10.5194/acp-9-3505-2009, 2009

Lamarque, J.-F., Bond, T. C., Eyring, V., Granier, C., Heil, A., Klimont, Z., Lee, D., Liousse, C., Mieville, A., Owen, B., Schultz, M. G., Shindell, D., Smith, S. J., Stehfest, E., Van Aardenne, J., Cooper, O. R., Kainuma, M., Mahowald, N., McConnell, J. R., Naik, V., Riahi, K., and van Vuuren, D. P.: Historical (1850-2000) gridded anthropogenic and biomass burning emissions of reactive gases and aerosols: methodology and application, Atmos. Chem. Phys., 10, 7017-7039, doi:10.5194/acp10-7017-2010, 2010.

Lawson, R. P., O’Connor, D., Zmarzly, P., Weaver, K., Baker, B., Mo, Q., and Jonsson, H.: The 2D-S (stereo) probe: design and preliminary tests of a new airborne, high-speed, high-resolution particle imaging probe, J. Atmos. Ocean. Technol., 23, 1462 1477, doi:10.1175/JTECH1927.1, 2006.

Lawson, R. P.: Effects of ice particles shattering on the 2D-S probe, Atmos. Meas. Tech., 4, 1361-1381, doi:10.5194/amt-4-13612011, 2011.

Lin, R.-F.: A numerical study of the evolution of nocturnal cirrus by a two-dimensional model with explicit microphysics, $\mathrm{PhD}$ thesis, The Pennsylvania State University, Pennsylvania, 199 pp., 1997.

Lin, R. F., Starr, D., DeMott, P., Cotton, R., Sassen, K., Jensen, E., Kärcher, B., and Liu, X.: Cirrus parcel model comparison project. Phase 1: the critical components to simulate cirrus initiation explicitly, J. Atmos. Sci., 59, 2305-2329, doi:10.1175/15200469(2002)059<2305:CPMCPP>2.0.CO;2, 2002.

Liu, X. and Penner, J.: Ice nucleation parameterization for a global model, Meteorol. Z., 14, 499-514, doi:10.1127/09412948/2005/0059, 2005.

Liu, X. H. and Seidl, W.: Modeling study of cloud droplet nucleation and in-cloud sulfate production during the SANA2 campaign, J. Geophys. Res., 103, 16145-16158, doi:10.1029/98JD00972, 1998.

Liu, X. H., Penner, J. E., Ghan, S. J., and Wang, M. H.: Inclusion of ice microphysics in the NCAR community atmospheric model version 3 (CAM3), J. Climate, 20, 4526-4547, doi:10.1175/JCLI4264.1, 2007.

Liu, X., Easter, R. C., Ghan, S. J., Zaveri, R., Rasch, P., Shi, X., Lamarque, J.-F., Gettelman, A., Morrison, H., Vitt, F., Con- 
ley, A., Park, S., Neale, R., Hannay, C., Ekman, A. M. L., Hess, P., Mahowald, N., Collins, W., Iacono, M. J., Bretherton, C. S., Flanner, M. G., and Mitchell, D.: Toward a minimal representation of aerosols in climate models: description and evaluation in the Community Atmosphere Model CAM5, Geosci. Model Dev., 5, 709-739, doi:10.5194/gmd-5-709-2012, 2012a.

Liu, X., Shi, X., Zhang, K., Jensen, E. J., Gettelman, A., Barahona, D., Nenes, A., and Lawson, P.: Sensitivity studies of dust ice nuclei effect on cirrus clouds with the Community Atmosphere Model CAM5, Atmos. Chem. Phys., 12, 12061-12079, doi:10.5194/acp-12-12061-2012, 2012 b.

Lohmann, U. and Hoose, C.: Sensitivity studies of different aerosol indirect effects in mixed-phase clouds, Atmos. Chem. Phys., 9, 8917-8934, doi:10.5194/acp-9-8917-2009, 2009.

Lohmann, U., Spichtinger, P., Jess, S., Peter, T., and Smit, H.: Cirrus cloud formation and ice supersaturated regions in a global climate model, Environ. Res. Lett., 3, 045022, doi:http://dx.doi.org/10.1088/17489326/3/4/04502210.1088/1748-9326/3/4/045022, 2008.

Mace, G. G., Zhang, Y., Platnick, S., King, M. D., Minnis, P., and Yang, P.: Evaluation of cirrus cloud properties derived from MODIS data using cloud properties derived from ground-based observations collected at the ARM SGP site, J. Appl. Meteorol., 44, 221-240, doi:10.1175/JAM2193.1, 2005.

Magee, N., Moyle, A. M., and Lamb, D.: Experimental determination of the deposition coefficient of small cirrus-like ice crystals near $-50{ }^{\circ} \mathrm{C}$, Geophys. Res. Lett., 33, L17813, doi:10.1029/2006GL026665, 2006.

McFarquhar, G. M., Um, J., Freer, M., Baumgardner, D., Kok, G. L., and Mace, G.: Importance of small ice crystals to cirrus properties: Observations from the Tropical Warm Pool International Cloud Experiment (TWP-ICE), Geophys. Res. Lett., 34, L13803, doi:10.1029/2007GL029865, 2007.

Meyers, M. P., Demott, P. J., and Cotton, W. R.: New primary ice-nucleation parameterizations in an explicit cloud model, J. Appl. Meteorol., 31, 708-721, doi:10.1175/15200450(1992)031<0708:NPINPI>2.0.CO;2, 1992.

Mitchell, D.: Effective diameter in radiation transfer: general definition, applications, and limitations, J. Atmos. Sci., 59, 2330-2346, doi:10.1175/1520-0469(2002)059<2330:EDIRTG > 2.0.CO;2, 2002.

Mitchell, D. L., Rasch, P., Ivanova, D., McFarquhar, G., and Nousiainen, T.: Impact of small ice crystal assumptions on ice sedimentation rates in cirrus clouds and GCM simulations, Geophys. Res. Lett., 35, 9806, doi:10.1029/2008GL033552, 2008.

Mitchell, D. L., Lawson, R. P., and Baker, B.: Understanding effective diameter and its application to terrestrial radiation in ice clouds, Atmos. Chem. Phys., 11, 3417-3429, doi:10.5194/acp11-3417-2011, 2011.

Mlawer, E. J., Taubman, S. J., Brown, P. D., Iacono, M. J., , and Clough, S. A.: Radiative transfer for inhomogeneous atmospheres: RRTM, a validated correlated- $k$ model for the longwave, J. Geophys. Res., 102, 16663-16682, 1997.

Möhler, O., Field, P. R., Connolly, P., Benz, S., Saathoff, H., Schnaiter, M., Wagner, R., Cotton, R., Krämer, M., Mangold, A., and Heymsfield, A. J.: Efficiency of the deposition mode ice nucleation on mineral dust particles, Atmos. Chem. Phys., 6, 30073021, doi:10.5194/acp-6-3007-2006, 2006.
Morrison, H. and Gettelman, A.: A new two-moment bulk stratiform cloud microphysics scheme in the NCAR Community Atmosphere Model (CAM3), Part I: Description and numerical tests, J. Climate, 21, 3642-3659, doi:10.1175/2008JCLI2105.1, 2008.

Murray, B. J., Wilson, T. W., Dobbie, S., Cui, Z., Al-Jumur, S. M. R. K., Möhler, O., Schnaiter, M., Wagner, R., Benz, S., Niemand, M., Saathoff, H., Ebert, V., Wagner, S., and Kärcher, B.: Heterogeneous nucleation of ice particles on glassy aerosols under cirrus conditions, Nature Geosci., 3, 233-237, doi:10.1038/ngeo817, 2010.

Neale, R. B., Chen, C. C., Gettelman, A., Lauritzen, P. H., Park, S., Williamson, D. L., Conley, A. J., Garcia, R., Kinnison, D., Lamarque, J. F., Marsh, D., Mills, M., Smith, A. K., Tilmes, S., Vitt, F., Morrison, H., Cameron-Smith, P., Collins, W. D., Iacono, M. J., Easter, R. C., Ghan, S. J., Liu, X. H., Rasch, P. J., and Taylor, M. A.: Description of the NCAR Community Atmosphere Model (CAM5.0), Tech. Rep. NCAR/TN-486-STR, NCAR, available at: http://www.cesm.ucar.edu/models/cesm1.0/ cam/ (last access: 8 January 2013), 2010.

Ovarlez, J., Gayet, J. F., Gierens, K., Stroem, J., Ovarlez, H., Auriol, F., Busen, R., and Schumann, U.: Water vapour measurements inside cirrus clouds in Northern and Southern Hemispheres during INCA, Geophys. Res. Lett., 29, 1813, doi:10.1029/2001GL014440, 2002.

Park, S. and Bretherton, C. S.: The University of Washington shallow convection and moist turbulence schemes and their impact on climate simulations with the Community Atmosphere Model, J. Climate, 22, 3449-3469, doi:10.1175/2008JCLI2557.1, 2009.

Park, S., Bretherton, C. S., and Rasch, P. J.: Global cloud simulation in the Community Atmosphere Model 5, J. Climate, submitted, 2012.

Phillips, V. T. J., DeMott, P. J., and Andronache, C.: An empirical parameterization of heterogeneous ice nucleation for multiple chemical species of aerosol, J. Atmos. Sci., 65, 2757-2783, doi:10.1175/2007JAS2546.1, 2008.

Prenni, A. J., DeMott, P. J., Twohy, C., Poellot, M. R., Kreidenweis, S. M., Rogers, D. C., Brooks, S. D., Richardson, M. S., and Heymsfield, A. J.: Examinations of ice formation processes in Florida cumuli using ice nuclei measurements of anvil ice crystal particle residues, J. Geophys. Res.-Atmos., 112, 10221, doi:10.1029/2006JD007549, 2007.

Pruppacher, H. R. and Klett, J. D.: Microphysics of Clouds and Precipitation, 2nd edn., Springer, New York, USA, 1997.

Richter, J. H. and Rasch, P. J.: Effects of convective momentum transport on the atmospheric circulation in the community atmosphere model, version 3, J. Climate, 21, 1487-1499, doi:10.1175/2007JCLI1789.1, 2008.

Salzmann, M., Ming, Y., Golaz, J.-C., Ginoux, P. A., Morrison, H., Gettelman, A., Krämer, M., and Donner, L. J.: Two-moment bulk stratiform cloud microphysics in the GFDL AM3 GCM: description, evaluation, and sensitivity tests, Atmos. Chem. Phys., 10, 8037-8064, doi:10.5194/acp-10-8037-2010, 2010.

Sassen, K. and Dodd, G. C.: Homogeneous nucleation rate for highly supercooled cirrus cloud droplets, J. Atmos. Sci., 45, 1357-1369, doi:10.1175/15200469(1988)045<1357:HNRFHS > 2.0.CO;2, 1988.

Skrotzki, J., Connolly, P., Schnaiter, M., Saathoff, H., Möhler, O., Wagner, R., Niemand, M., Ebert, V., and Leisner, T.: The accom- 
modation coefficient of water molecules on ice - cirrus cloud studies at the AIDA simulation chamber, Atmos. Chem. Phys., 13, 4451-4466, doi:10.5194/acp-13-4451-2013, 2013.

Smith, W. L., Ackerman, S., Revercomb, H., Huang, H., DeSlover, D. H., Feltz, W., Gumley, L., and Collard, A.: Infrared spectral absorption of nearly invisible cirrus clouds, Geophys. Res. Lett., 25, 1137-1140, doi:10.1029/97GL03491, 1998.

Spice, A., Johnson, D. W., Brown, P. R. A., Darlison, A. G., and Saunders, C. P. R.: Primary ice nucleation in orographic cirrus clouds: a numerical simulation of the microphysics, Q. J. Roy. Meteorol. Soc., 125, 1637-1667, doi:10.1002/qj.49712555708, 1999.

Spichtinger, P. and Gierens, K. M.: Modelling of cirrus clouds - Part 2: Competition of different nucleation mechanisms, Atmos. Chem. Phys., 9, 2319-2334, doi:10.5194/acp-9-2319-2009, 2009.

Spichtinger, P., Gierens, K., Smit, H. G. J., Ovarlez, J., and Gayet, J.-F.: On the distribution of relative humidity in cirrus clouds, Atmos. Chem. Phys., 4, 639-647, doi:10.5194/acp-4639-2004, 2004.

Tabazadeh, A., Martin, S. T., and Lin, J.-S.: The effect of particle size and nitric acid uptake on the homogeneous freezing of aqueous sulfuric acid particles, Geophys. Res. Lett., 27, 1111-1114, doi:10.1029/1999GL010966, 2000.
Wang, M. and Penner, J. E.: Cirrus clouds in a global climate model with a statistical cirrus cloud scheme, Atmos. Chem. Phys., 10, 5449-5474, doi:10.5194/acp-10-5449-2010, 2010.

Young, K.: A numerical simulation of wintertime, orographic precipitation. Part I: Description of model microphysics and numerical technique, J. Atmos. Sci., 31, 1735-1748, doi:10.1175/15200469(1974)031<1735:ANSOWO>2.0.CO;2, 1974.

Yun, Y. and Penner, J. E.: Global model comparison of heterogeneous ice nucleation parameterizations in mixed phase clouds, J. Geophys. Res., 117, 7203, doi:10.1029/2011JD016506, 2012.

Zhang, G. J. and McFarlane, N. A.: Sensitivity of climate simulations to the parameterization of cumulus convection in the Canadian Climate Centre general circulation model, Atmos.-Ocean, 33, 407-446, 1995.

Zhao, C., Liu, X., Qian, Y., Yoon, J.-H., Hou, Z., Lin, G., McFarlane, S., Wang, H., Yang, B., Ma, P.-L., Yan, H., and Bao, J.: A Sensitivity Study of Radiative Fluxes at the Top of Atmosphere to Cloud-Microphysics and Aerosol Parameters in the Community Atmosphere Model CAM5, Atmos. Chem. Phys. Discuss., 13, 12135-12176, doi:10.5194/acpd-13-12135-2013, 2013. 